\title{
Cell Adhesion Factors in the Orbitofrontal Cortex Control Cue-Induced Reinstatement of Cocaine Seeking and Amygdala-Dependent Goal Seeking
}

\author{
Alonzo J. Whyte, ${ }^{1,2}$ Gracy Trinoskey-Rice, ${ }^{1,2}$ Rachel A. Davies, ${ }^{1,2}$ Ellen P. Woon, ${ }^{1,2,3}$ Stephanie L. Foster, ${ }^{1,2,3}$ \\ Lauren P. Shapiro, ${ }^{1,2,4}$ Dan C. Li, ${ }^{1,2,3}$ Kolluru D. Srikanth, ${ }^{5}$ Hava Gil-Henn, ${ }^{5}$ and Shannon L. Gourley ${ }^{1,2,3,4,6}$ \\ ${ }^{1}$ Departments of Pediatrics and Psychiatry, Emory University School of Medicine, Atlanta, Georgia 30329, ${ }^{2}$ Yerkes National Primate Research \\ Center, Emory University, Atlanta, Georgia 30329, ${ }^{3}$ Graduate Program in Neuroscience, Emory University, Atlanta, Georgia 30329, ${ }^{4}$ Graduate \\ Program in Molecular and Systems Pharmacology, Emory University, Atlanta, Georgia 30329, ${ }^{5}$ Azrieli Faculty of Medicine, Bar-Ilan University, \\ Safed, Israel, and ${ }^{6}$ Children's Healthcare of Atlanta, Atlanta, Georgia 30329
}

Repeated cocaine exposure causes dendritic spine loss in the orbitofrontal cortex, which might contribute to poor orbitofrontal cortical function following drug exposure. One challenge, however, has been verifying links between neuronal structural plasticity and behavior, if any. Here we report that cocaine self-administration triggers the loss of dendritic spines on excitatory neurons in the orbitofrontal cortex of male and female mice (as has been reported in rats). To understand functional consequences, we locally ablated neuronal $\beta 1$-integrins, cell adhesion receptors that adhere cells to the extracellular matrix and thus support dendritic spine stability. Degradation of $\beta 1$-integrin tone: (1) caused dendritic spine loss, (2) exaggerated cocaine-seeking responses in a cue-induced reinstatement test, and (3) impaired the ability of mice to integrate new learning into familiar routines, a key function of the orbitofrontal cortex. Stimulating Abl-related gene kinase, overexpressing Prolinerich tyrosine kinase, and inhibiting Rho-associated coiled-coil containing kinase corrected response strategies, uncovering a $\beta 1$-integrin-mediated signaling axis that controls orbitofrontal cortical function. Finally, use of a combinatorial gene silencing/chemogenetic strategy revealed that $\beta 1$-integrins support the ability of mice to integrate new information into established behaviors by sustaining orbitofrontal cortical connections with the basolateral amygdala.

Key words: Abl2; CD29; Itgb1; matrix; orbital; relapse

Significance Statement

Cocaine degenerates dendritic spines in the orbitofrontal cortex, a region of the brain involved in interlacing new information into established behaviors. One challenge has been verifying links between cellular structural stability and behavior, if any. In this second of two related investigations, we study integrin family receptors, which adhere cells to the extracellular matrix and thereby stabilize dendritic spines (see also DePoy et al., 2019). We reveal that $\beta 1$-integrins in the orbitofrontal cortex control food- and cocaine-seeking behaviors. For instance, $\beta 1$-integrin loss amplifies cocaine-seeking behavior and impairs the ability of mice to integrate new learning into familiar routines. We identify likely intracellular signaling partners by which $\beta 1$-integrins support orbitofrontal cortical function and connectivity with the basolateral amygdala.

Received Apr. 3, 2020; revised Mar. 15, 2021; accepted Mar. 16, 2021.

Author contributions: A.J.W., R.A.D., E.P.W., S.L.F., L.P.S., D.C.L., H.G.-H., and S.L.G. designed research; A.J.W., G.T.-R., R.A.D., E.P.W., S.L.F., L.P.S., D.C.L., K.D.S., and S.L.G. performed research; A.J.W., G.T.-R., R.A.D., E.P.W., S.L.F., L.P.S., D.C.L., K.D.S., H.G.H., and S.L.G. analyzed data; A.J.W. and S.L.G. wrote the first draft of the paper; A.J.W., G.T.-R., R.A.D., H.G.-H., and S.L.G. edited the paper; S.L.G. wrote the paper.

This work was supported by National Institutes of Health MH117103 and DA044297, and the Children's Healthcare of Atlanta and Emory University's Pediatric Integrated Cellular Imaging Core. The Yerkes National Primate Research Center is supported by National Institutes of Health OD011132. We thank Dr. Lauren DePoy for guidance with cocaine self-administration experiments; Aylet Allen for illustrations and surgical assistance, and quantification of Pyk2; and Drs. Bryan Roth and R. Jude Samulski (UNC Viral Vector Core) for the chemogenetic tools used here.

The authors declare no competing financial interests.

Correspondence should be addressed to Shannon L. Gourley at shannon.I.gourley@emory.edu.

https://doi.org/10.1523/JNEUROSCI.0781-20.2021

Copyright $\odot 2021$ the authors

\section{Introduction}

The orbitofrontal cortex (OFC) is a cortical structure affected by addictive drugs. Dependent cocaine users have diminished OFC gray matter volume (Mackey and Paulus, 2013); and psychostimulants cause dendrite and dendritic spine loss on excitatory OFC neurons in rodents, setting the OFC apart from other regions of the brain, where these drugs instead trigger spinogenesis (DePoy and Gourley, 2015). These structural modifications may contribute to poor OFC function with repeated drug exposure (Lucantonio et al., 2012). One challenge, however, has been verifying links between drug-induced structural plasticity and behavior, if any. 
The OFC is particularly important for integrating new or surprising information into familiar behaviors (Wilson et al., 2014; Stalnaker et al., 2015). For instance, assimilating new information regarding whether established behaviors will lead to desired outcomes requires the OFC (Jackson et al., 2016; Zimmermann et al., 2017, 2018; Parkes et al., 2018) and induces structural plasticity on OFC neurons (Whyte et al., 2019). Specifically, new learning triggers a reduction of immature, thin-type dendritic spines on excitatory neurons in the ventrolateral OFC (vlOFC) of mice, increasing the proportion of mature, mushroom-shaped spines (Whyte et al., 2019). These modifications may provide a neural substrate by which updated expectations are solidified. Consistent with this notion, instrumental response updating is associated with high densities of mature, mushroom-shaped spines in the anterior vlOFC (Barfield and Gourley, 2019).

Cocaine causes dendrite and dendritic spine loss on excitatory neurons in the vlOFC (Gourley et al., 2012; DePoy et al., 2014, 2017), critically including mature, mushroom-shaped spines (Radley et al., 2015). Cocaine-induced neuron atrophy could contribute to the difficulties of cocaine-exposed organisms with integrating new knowledge into familiar routines (Everitt and Robbins, 2016; Gourley and Taylor, 2016) and updating rewardrelated predictions based on prior experience (Lim et al., 2019; Takahashi et al., 2019). Here we investigate structure-function relationships between vlOFC neurons and the strategies by which mice respond for food and cocaine alike.

Our focus is on integrins, heterodimeric $(\alpha / \beta)$ cell adhesion receptors for extracellular matrix proteins, such as laminin, Reelin, and others (Lilja and Ivaska, 2018). The $\alpha$ subunit typically determines the extracellular binding partner, whereas the $\beta$ subunit determines intracellular partners: cytoskeletal regulatory elements that form and stabilize dendrites and dendritic spines (Kerrisk and Koleske, 2013; Park and Goda, 2016). $\beta 1$-integrins are expressed throughout the nervous system, including in the postnatal vlOFC (Shapiro et al., 2017a) and excitatory synapse postsynaptic densities (Schuster et al., 2001; Mortillo et al., 2012). Integrins, their ligands, and intracellular signaling partners in the nucleus accumbens control cocaine seeking in rats, linking cell adhesion with reward-seeking behavior (Toda et al., 2006; Wiggins et al., 2011; Garcia-Keller et al., 2019). Further prefrontal cortical, hippocampal, and striatal levels are modified by stressors and cocaine, including in cocaine-using humans (Morsink et al., 2006; Mash et al., 2007; Wiggins et al., 2009; Hinwood et al., 2013), with some gene expression changes detectable even in peripheral blood (Lo Iacono et al., 2017).

Here we impoverished dendritic spine densities on excitatory vlOFC neurons by reducing $\beta 1$-integrin levels. Integrin scarcity increased cocaine seeking and ablated the ability of mice to interlace new information into familiar response strategies, thus resembling effects of cocaine. We then identified likely neuronal intracellular signaling partners and vlOFC-BLA connections in which $\beta 1$-integrins are essential.

\section{Materials and Methods}

\section{Subjects}

For dendritic spine imaging studies, mice expressed Yellow Fluorescence Protein under the Thy1 promoter ( $\mathrm{H}$ line from Feng et al., 2000), bred on a C57BL/6 background, sourced from The Jackson Laboratory. These mice were crossed with mice that were homozygous for a floxed Itgb1 gene, which encodes $\beta 1$-integrins (Itbg1 $1^{\text {tmIEfu }}$ mice from Raghavan et al., 2000), bred on a mixed C57BL/6J;129 $\times 1 /$ SvJ background, sourced from The Jackson Laboratory. These double-transgenic mice allowed us to reduce $\beta 1$-integrin protein in the presence of virally expressed Cre-
Recombinase (Cre) and assess behavioral and anatomic consequences. In experiments in which Itgb1 was not manipulated, subjects were C57BL/6 mice bred in-house from The Jackson Laboratory stock. Mice were maintained on a $12 \mathrm{~h}$ light cycle ( $0700 \mathrm{on})$ and provided food and water ad libitum unless otherwise noted.

At the onset of behavioral testing, mice were food restricted to $\sim 90 \%-93 \%$ of their baseline body weight to energize food-reinforced responding. Mice used for protein quantification experiments did not undergo behavioral testing and were thus not food restricted. The timing of experimental events is provided in the individual sections below and figure timelines. All procedures were approved by the Institute of Animal Care and Use Committee at Emory University.

\section{Sex of mice}

Both sexes were used in our initial cocaine self-administration experiments, with no sex effects detected. In subsequent experiments manipulating Itgb1, males were used given that females are behaviorally resilient to vlOFC-targeted Itgb1 knockdown (DePoy et al., 2019), potentially because of interactions between spared $\beta 1$-integrins and estrogen-mediated excitatory synaptic plasticity (Wang et al., 2016).

\section{Viral vectors}

Adeno-associated viruses (AAVs) were AAV2/8-CaMKII-mCherry \pm Cre and AAV5-CaMKII-mCherry $\pm \mathrm{hM}_{4} \mathrm{D}$ (Gi) (University of North Carolina Viral Vector Core). For description of $\mathrm{hM}_{4} \mathrm{D}(\mathrm{Gi})$-designer receptors exclusively activated by designer drugs (DREADDs), see Urban and Roth (2015).

For $P t k 2 b$ overexpression, $P t k 2 b$ was isolated from a mouse embryonic fibroblast cDNA library using PCR, and then subcloned into a BamHI restriction site between the CMV promoter and the IRES-GFP sequence of the lentiviral expression vector pCSC-SP-PW-CMV-IRES/ GFP. Lentiviruses robustly infect neurons, although moderate glial infection would also be anticipated (Ehrengruber et al., 2001).

\section{Intracranial surgery}

Mice were anesthetized with $80 \mathrm{mg} / \mathrm{kg}$ ketamine and $0.5 \mathrm{mg} / \mathrm{kg}$ dexmedetomidine (i.p.) and placed in a digitized stereotaxic frame (Stoelting). The scalp was incised, skin retracted, bregma and $\lambda$ identified, the head leveled, and coordinates located. vlOFC infusions were delivered at AP 2.6, $\mathrm{ML} \pm 1.2, \mathrm{DV}-2.8$. BLA infusions were delivered at AP -1.3 , $\mathrm{ML} \pm 3.0$, DV -4.9. Dorsomedial striatum (DMS) infusions were delivered at AP $0.5, \mathrm{ML} \pm 1.5$, DV -4.25 . Volumes were $0.5 \mu \mathrm{l} /$ infusion delivered over $5 \mathrm{~min}$. Needles were left in place for 5 additional minutes before withdrawal and suture.

We infused Cre- and DREADDs-expressing viral vectors just before adolescence, at postnatal day (P) 24 . We chose this timing because $\beta 1$ integrins are essential for neuron development during the adolescent period, ensuring complex, spine- and synapse-adorned neurons in adulthood (Warren et al., 2012; DePoy et al., 2019) (see Fig. 1). Mice were allowed $\sim 32 \mathrm{~d}$ to recover before behavioral testing or jugular vein catheterization.

For $P t k 2 b$ overexpression, viral vectors were delivered at P56 ( \pm 1 week). Then, mice were allowed to recover for 2-3 weeks.

\section{Cocaine versus food self-administration}

Preparation of mice

These experiments compared mice nose poking for cocaine or food reinforcement, or mice responding for cocaine with or without $\beta 1$-integrin deficiency. Mice were first familiarized with reinforced nose poking. They were all initially trained to nose poke for food $(20 \mathrm{mg}$ grain-based pellets; Bio-Serv) in Med Associates conditioning chambers for 2 or 3 sessions identical to those described in Nose poke training, below. The conditioning chambers were distinct from the chambers used for the next phase of testing.

\section{Catheter placement}

Mice were then anesthetized with a mixture of $80 \mathrm{mg} / \mathrm{kg}$ ketamine and $0.5 \mathrm{mg} / \mathrm{kg}$ dexmedetomidine (i.p.). In mice designated to respond for cocaine, an indwelling catheter (Silastic silicone tubing) was implanted in 
A P56 catheterization, training $\rightarrow 2$ weeks $\rightarrow$ dendritic spine imaging
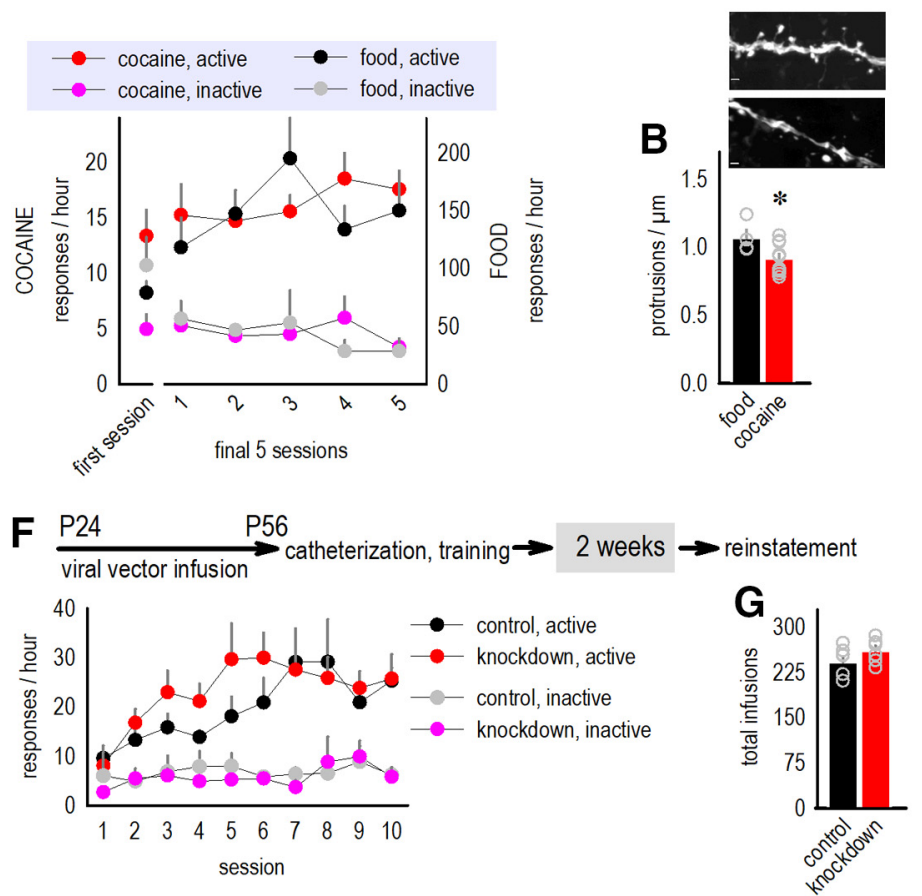

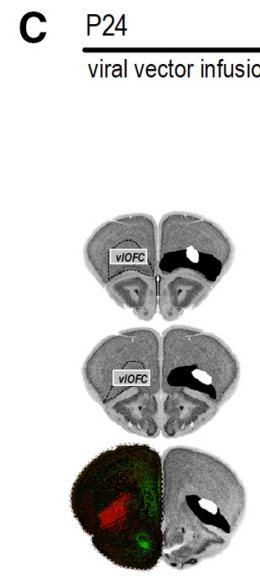

$\stackrel{P 56}{\rightarrow}$
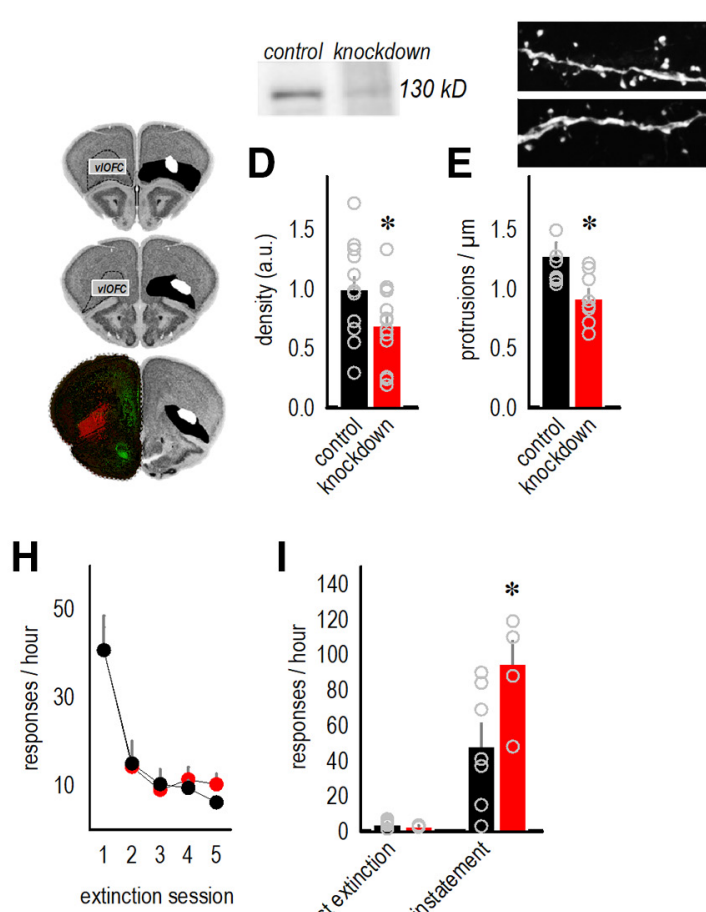

I

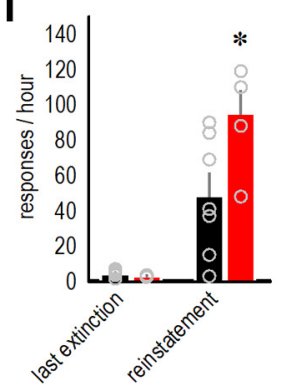

Figure 1. Cocaine self-administration causes dendritic spine loss in the vlOFC, while the cell adhesion factor $\beta$ 1-integrin confers resilience to cocaine-seeking behavior. $\boldsymbol{A}$, Timeline. Intact mice were trained to respond for food or cocaine. The first and final sessions are shown ( $n=10$ cocaine, $n=4$ food). $B$, Dendritic spine densities on excitatory vlOFC neurons were lower in the cocaine-reinforced mice, as in rats (see Radley et al., 2015). Top, Representative dendrites. C, We next delivered Cre to the vlOFC of Itgb1-flox mice. Top, Timeline. Bottom, Images indicate large and small representative viral vector spread on coronal sections from the Mouse Brain Library (Rosen et al., 2000). Red indicates a representative infusion. $\boldsymbol{D}, \beta 1$-integrin levels were lower in gross tissue punches collected from the vlOFC of knockdown mice. Incomplete protein loss was expected, given that tissue punches contained both transfected and uninfected cells. Top, Representative blots ( $n=18$ control, $n=20$ knockdown). $\boldsymbol{E}$, Itgb1 knockdown caused dendritic spine loss, as with cocaine ( $n=8 /$ group). Top, Representative dendrites. $\boldsymbol{F}$, Top, Timeline. Itgb1 knockdown did not impact cocaine self-administration. $\boldsymbol{G}$, Groups accumulated the same amount of cocaine before $(\boldsymbol{H})$ extinction conditioning. $\boldsymbol{I}$, When cocaine-associated cues were presented, knockdown mice generated more responses than control mice. The final day of extinction conditioning is represented for reference $(n=7$ control, $n=6 \mathrm{knockdown})$. Closed symbols and bars represent mean + SEM. ${ }^{*} p<0.05$. Open symbols represent individual mice. Mice generating the same values will not be distinguishable. Scale bars, $1 \mu \mathrm{m}$. Dendrites were analyzed by independent, blinded raters, and Itgb 1 knockdown experiments were conducted twice. All groups were included in each replicate; both replications are represented here.

the right jugular vein as previously described (Thomsen and Caine, 2005). Mice designated to the food-reinforced condition were anesthetized identically, but no catheter was placed.

\section{Confirmation of catheter patency}

Mice were singly housed and allowed $7 \mathrm{~d}$ to recover, during which catheter patency was maintained via daily intravenous infusion of $0.05 \mathrm{ml}$ heparin in saline; $24 \mathrm{~h}$ before the initiation of cocaine self-administration training and weekly thereafter, catheter patency was confirmed via infusion of $0.03 \mathrm{ml}$ ketamine $(15 \mathrm{mg} / \mathrm{ml})$. Mice that did not exhibit loss of muscle tone within $10 \mathrm{~s}$ of ketamine infusion were excluded.

\section{Self-administration}

Mice were trained to self-administer intravenously delivered cocaine using a fixed ratio 1 (FR1) schedule of reinforcement. A $20 \mu \mathrm{l}, 1.25 \mathrm{mg} /$ $\mathrm{kg}$ infusion of cocaine was delivered on nose poke in the center of three nose poke ports. Each infusion coincided with the extinction of the house light for $20 \mathrm{~s}$, signaling cocaine delivery and a timeout period during which no additional responses elicited cocaine delivery. Each session lasted until the mice obtained 30 infusions or reached the maximum duration of $2 \mathrm{~h}$. At the end of each session, catheters were flushed with heparin solution, and mice were returned to their home cages.

Maintenance criteria were achieved when, over 2 consecutive days, a mouse: acquired $>20$ infusions and $>20 \mathrm{mg} / \mathrm{kg}$ cocaine, had $<30 \%$ responding on the inactive nose poke ports compared with the active ports, and had $<20 \%$ intersession variability in response rates. Mice were tested daily, with 1 session/day.
In the experiment in which we compared food versus cocaine selfadministering mice, food was delivered according to the same conditions as cocaine.

\section{Response extinction}

Mice were placed in the operant conditioning chambers and tethered, as during the cocaine self-administration procedure; however, cocaine was not delivered, and neither cues (house light off; pump on) were activated following responses on the previously active nose poke port. Mice were tested daily, with 1 session/day. Mice attained response extinction criteria when responses rates on the previously active ports were $<25 \%$ of response rates on the last training day, at which point training was discontinued. All mice underwent a minimum of 52 -h extinction training sessions; thus, the first 5 and the final extinction sessions are represented graphically. One mouse unexpectedly died during extinction conditioning; that mouse's response extinction data were removed.

\section{Cue-induced reinstatement}

In a single $60 \mathrm{~min}$ session, mice received one noncontingent cue presentation (house light off; pump on), followed by contingent cue presentations on responding on the previously active ports. Cocaine was not delivered.

\section{Experimental designs}

Experiment 1

When mice reached maintenance criteria, training was discontinued, and mice were left undisturbed in the home cage for $14 \mathrm{~d}$ and then killed, 

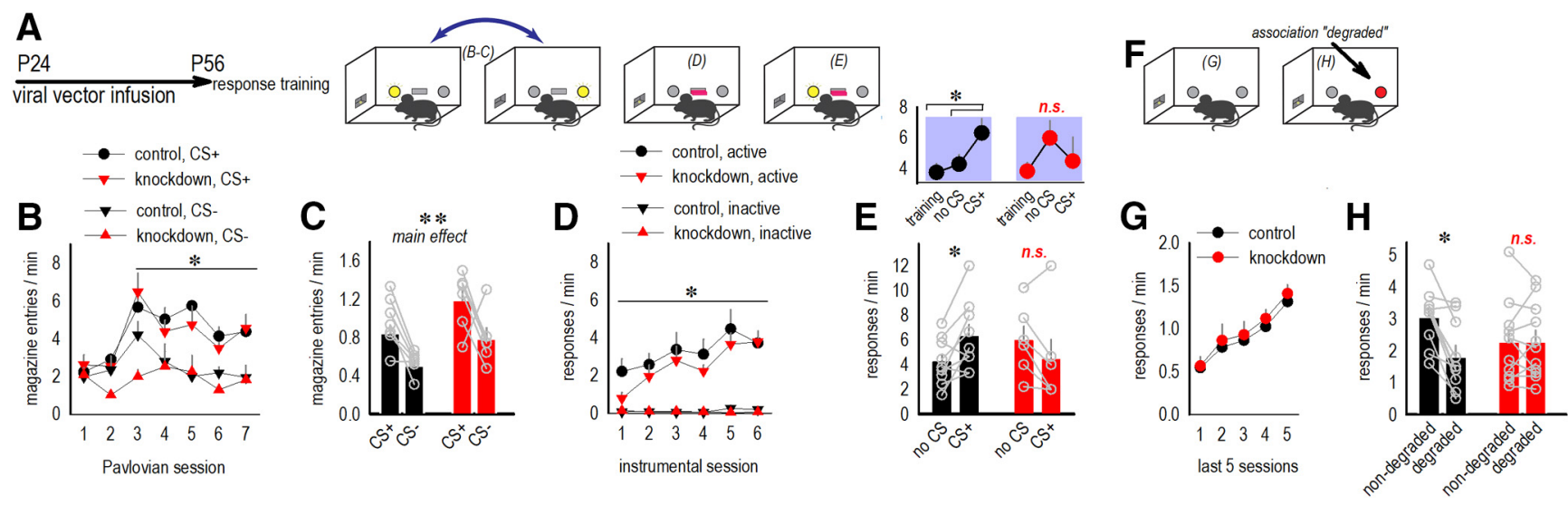

Figure 2. $\quad \beta$ 1-integrins in the vIOFC are necessary for updating goal-seeking behavior. $\boldsymbol{A}$, Left, Timeline. Right, Mice were trained to associate one sustained light with food (CS ${ }^{+}$) and one with no food (CS) in a counterbalanced order. Next, mice were trained to press a previously recessed lever for food. In a probe test, the $\mathrm{CS}^{+}$was presented with the lever. Letters in parentheses correspond to the figures below. $\boldsymbol{B}$, During Pavlovian training, mice entered the magazine more during the $\mathrm{CS}^{+}$, with no group differences. $\boldsymbol{C}$, Pavlovian conditioning was further confirmed by presenting the CS's in short, alternating epochs and measuring magazine entries; again, mice entered the magazine more during the $\mathrm{CS}^{+}$, with no group differences $(n=7$ control, $n=6$ knockdown). D, During instrumental conditioning, mice generated a food-reinforced lever press and neglected "inactive" nose poke ports, at which responding was not reinforced. Groups did not differ. $\boldsymbol{E}$, During a probe test, however, control mice generated more lever presses when the $\mathrm{CS}^{+}$was present, relative to the no-CS periods. Meanwhile, response rates were not sensitive to testing phase in knockdown mice. Top, Data are presented in line graph form, including the final day of training. Response rates during the probe test are recapitulated with individual data points at bottom ( $n=9$ control, $n=6$ knockdown; 6 mice with misplaced viral vectors were excluded). $\boldsymbol{F}$, Separate mice were trained in the absence of explicit stimuli to nose poke on two ports for food pellets. Then, the predictive relationship between one response and the associated pellet was weakened when responding ceased to be reinforced. In a probe test, response preference was measured. $\boldsymbol{G}$, Response rates across training are shown; responses are collapsed across ports for simplicity, and groups did not differ. $\boldsymbol{H}$, When one response was no longer reinforced and instead, pellets associated with that response were delivered noncontingently ("degraded" condition), control mice favored the other behavior, which remained likely to be reinforced ("nondegraded" condition). Meanwhile, knockdown mice failed to adjust response preferences, responding equivalently, as during training ( $n=10$ control, $n=11$ knockdown). Closed symbols and bars represent mean + SEM. ${ }^{*} p<0.05$. Open symbols represent individual mice. d, days. Experiments were conducted at least twice; all groups were included and are represented here.

the goal being to assess the long-term consequences of cocaine selfadministration on dendritic spine densities (see Fig. 1, top). Mice in this experiment reached maintenance criteria within 5-13 sessions, so the associated graph represents the first and final 5 sessions for all mice.

\section{Experiment 2}

In the experiment in which we reduced Itgb1, all mice self-administered cocaine for 10 initial training sessions to determine whether gene silencing affected cocaine self-administration patterns (see Fig. 1, bottom). Then, mice underwent extinction conditioning. Next, mice were left undisturbed in the home cage for $14 \mathrm{~d}$ to match the timing of euthanasia in the experiment above, and cue-induced reinstatement of responding was tested.

\section{Additional food-reinforced experiments}

Mice were tested at or soon after P56. Med Associates conditioning chambers were equipped with 2 nose poke ports with recessed lights, a retractable lever, a separate food magazine, and a house light.

\section{Experiment 1}

Pavlovian conditioning. For 760 min sessions, Pavlovian conditioning occurred, during which the nose poke lights served as conditioned stimuli (CS): 1 light, which served as the $\mathrm{CS}^{+}$, was illuminated for $30 \mathrm{~min}$ while a food pellet $(20 \mathrm{mg}$ grain-based pellets; Bio-Serv) was delivered every $30 \mathrm{~s}$ (see Fig. 2, left). The other light, which was the CS${ }^{-}$, was illuminated for $30 \mathrm{~min}$, during which no food was delivered. The lights were positioned on opposite sides of 1 wall of the chamber. The order of the $\mathrm{CS}^{+}$versus $\mathrm{CS}^{-}$periods was randomized across days, such that roughly half of the mice received the $\mathrm{CS}^{+}$first on any given day, and the order of the $\mathrm{CS}^{+}$versus $\mathrm{CS}^{-}$presentation across days was not predictable. Mice were tested daily, with 1 session/day, and magazine entries were recorded.

One group of mice proceeded to lever-press training, described in the next section. In another group of mice, the efficacy of Pavlovian conditioning was confirmed using a $3 \mathrm{~h}$ test in which the $\mathrm{CS}^{+}$and $\mathrm{CS}^{-}$were presented in an alternating fashion for $30 \mathrm{~s}$, and their presentation was terminated with pellet delivery in case of the $\mathrm{CS}^{+}$and no pellet in the case of $\mathrm{CS}^{-}$. A $30 \mathrm{~s}$ intertrial interval separated them, and magazine entries during the $\mathrm{CS}^{+}$and $\mathrm{CS}^{-}$were compared.

Lever press training. The house light was illuminated, the lever was extended, and lever-pressing was reinforced according to an FR1 schedule for $30 \mathrm{~min}$ for 6 sessions. Head entries into the nose poke ports were recorded but had no programmed consequences. Mice were tested daily, with 1 session/day.

Probe test. The lever was extended, the house light was illuminated, and after a $2 \mathrm{~min}$ habituation period, the $\mathrm{CS}^{+}$was presented in $3 \times 30 \mathrm{~s}$ increments, with $30 \mathrm{~s}$ between each $\mathrm{CS}^{+}$presentation and a final minute with no $\mathrm{CS}^{+}$. The lever remained extended throughout the entire test. Lever-press response rates during the entirety of the $\mathrm{CS}^{+}$versus no CS periods were compared. No food was delivered.

\section{Experiment 2}

Nose poke training. Mice were trained to nose poke on both available nose poke ports for unsignaled food reinforcement $(20 \mathrm{mg}$ grain-based pellets; Bio-Serv) according to an FR1 schedule of reinforcement (see Fig. 2, right). Thirty pellets were available for responding on each nose poke port, for a total of 60 pellets per daily session. Daily sessions ended when mice acquired all 60 pellets or at $70 \mathrm{~min}$. Mice were considered to have acquired the task when they had obtained the maximum number of pellets within $70 \mathrm{~min}$, typically occurring within 5-7 training sessions. The final 5 sessions are represented. Mice did not display side biases that could affect response strategies in the next phase of testing.

Contingency degradation. Next, we subjected mice to a modified instrumental contingency degradation procedure, conducted as in our prior reports (e.g., Swanson et al., 2017) and similar to the method of Barker et al. (2013). One nose poke port was blocked, and responding on the remaining port was reinforced for $25 \mathrm{~min}$. The next day, the other port was blocked. On this day, responding produced no consequences. Instead, pellets were delivered into the magazine for $25 \mathrm{~min}$ at a rate yoked to each individual mouse's pellet delivery rate from the prior session. Thus, the response-reward contingency associated with this nose poke behavior was violated. Whether this violation occurred at the left or right port was randomized.

Probe test. To determine whether mice integrated new information into familiar response strategies, mice underwent a 5-10 min probe test 
the following day. Both nose poke ports were available, and responses were quantified. Probe tests were conducted in extinction. Preferential responding on the "nondegraded" port demonstrates the integration of new information into established behaviors. Nondifferential responding reflects a failure in response updating.

\section{Drug dosing and timing \\ Cocaine}

Cocaine was purchased from Sigma Millipore. Intravenous delivery is described in Cocaine self-administration. Systemic administration occurred once daily from P31 to P35 (10 mg/kg, i.p.), dissolved in sterile saline, in accordance with our prior investigations regarding the longterm consequences of cocaine exposure (Gourley et al., 2012; DePoy et al., 2014, 2017).

Arg activation and rho-associated coiled-coil containing kinase (ROCK) inhibition

The small-molecule Arg activator, m5-(1,3-diaryl-1H-pyrazol-4-yl) hydantoin, 5-[3-(4-fluorophenyl)-1-phenyl-1H-pyrazol-4-yl]-2,4-imidazolidinedione (DPH; generously provided by Anthony Koleske), was suspended in sterile saline and $17 \%$ DMSO. The dose was $30 \mathrm{mg} / \mathrm{kg}$ (i.p.), selected because it increases the phosphorylation (activation) of the Arg substrate, p190RhoGAP, in the hippocampus (Shapiro et al., 2017b), evidence that systemic administration activates central Arg.

The ROCK inhibitor, fasudil (LKT Labs), was delivered at a dose of $10 \mathrm{mg} / \mathrm{kg}$ (i.p.), dissolved in sterile saline. The dose was selected because it can improve certain forms of learning and memory and trigger cortical dendritic spine plasticity (DePoy et al., 2017; Swanson et al., 2017; Hinton et al., 2019; Shapiro et al., 2019).

$\mathrm{DPH}$, fasudil, or their respective vehicles was delivered once daily from P32 to P39, chosen because levels of the Arg substrate p190RhoGAP and ROCK are high in the vlOFC during this period (Shapiro et al., 2017a) and based on investigations using similar timing to block long-term effects of early-life glucocorticoid excess (Barfield et al., 2017). When drugs were delivered on the same day as cocaine, they were prepared with cocaine and given simultaneously.

\section{Clozapine N-oxide (CNO)}

CNO (Sigma Millipore) was delivered at a dose of $1 \mathrm{mg} / \mathrm{kg}$ (i.p.), dissolved in 2\% DMSO and sterile saline. CNO was delivered immediately following the contingency degradation procedure, and mice were tested in the probe test the next day drug-free. This timing and dosing were chosen based on prior reports using bilateral vlOFC DREADDs placement to investigate vlOFC-dependent learning and memory (Zimmermann et al., 2017, 2018; Whyte et al., 2019). All mice received $\mathrm{CNO}$, regardless of condition, to equally expose animals to any unintended consequences of CNO (see Gomez et al., 2017). Importantly, this dose does not by itself impact responding in this task (Whyte et al., 2019). $100 \mathrm{~g}$.

Throughout, systemic injections were delivered in a volume of $1 \mathrm{ml} /$

\section{Histology}

Mice were deeply anesthetized and killed by decapitation or, more commonly, intracardiac perfusion. Brains were extracted, submerged in chilled $4 \%$ PFA for $48 \mathrm{~h}$, then transferred to chilled $30 \% \mathrm{w} / \mathrm{v}$ sucrose. Brains were later sectioned into $40 \mu \mathrm{m}$ coronal sections. Viral vector infusion sites were verified and characterized by imaging mCherry, which was enhanced via immunohistochemistry. Sections were washed $3 \times 5 \mathrm{~min}$ in PBS, followed by $1 \mathrm{~h}$ in PBS $+0.3 \%$ Triton, and then incubated overnight in a primary mouse anti-mCherry antibody (Living Colors, from Clontech) at 1:1000. Next, sections were washed $3 \times 5 \mathrm{~min}$ in PBS and incubated for $1 \mathrm{~h}$ in an Alexa-594 secondary antibody (Jackson ImmunoResearch Laboratories; 1:500). Last, sections were washed $3 \times 5 \mathrm{~min}$ in PBS, mounted to slides, and coverslipped with Vectashield mounting media.

\section{Dendritic spine imaging}

Brain preparation and imaging

Mice were killed by decapitation following rapid anesthesia under isoflurane. Brains were rapidly extracted and submerged in chilled $4 \%$ PFA for $48 \mathrm{~h}$, then transferred to $30 \% \mathrm{w} / \mathrm{v}$ sucrose, followed by sectioning into $50-\mu \mathrm{m}$-thick sections on a microtome held at $-15^{\circ} \mathrm{C}$. Unobstructed dendritic segments of neurons were imaged on a spinning disk confocal (VisiTech International) on a Leica Microsystems microscope. $z$ stacks were collected with a $100 \times 1.4 \mathrm{NA}$ objective using a $0.1 \mu \mathrm{m}$ step size, sampling above and below the dendrite. After imaging, we confirmed at $10 \times$ that the image was collected from the vlOFC.

Independent segments from secondary branches within $25-150 \mu \mathrm{m}$ of the soma were collected. Each protrusion $\leq 4.5 \mu \mathrm{m}$ was considered a dendritic spine. Bifurcated spines were considered singular units. Dendritic spines were counted manually by a single blinded rater using ImageJ software (1 rater/experiment), and spine number for each segment was divided by the length of the segment to generate spine densities. Each mouse contributed a single density value (its average) to statistical analyses.

\section{Experimental designs}

Experiment 1

Mice in cocaine self-administration experiments were killed $14 \mathrm{~d}$ following the final day of testing. Eight to 10 independent dendritic segments per mouse were imaged and scored (see Fig. 1B).

\section{Experiment 2}

To assess dendritic spine densities following Itgb1 silencing, we used banked tissues from DePoy et al. (2019) to conserve animal usage (see Fig. 1E). In this case, Yellow Fluorescence Protein-expressing Itgb1-flox mice had been infused into 1 hemisphere with AAV-mCherry and in the opposite hemisphere, AAV-mCherry-Cre, at P24. Mice were killed $32 \mathrm{~d}$ later, at P56, matching the timing of behavioral testing here. We imaged dendrites selectively within the anterior vlOFC (at or anterior to bregma 2.48), where dendritic spine density positively correlates with response updating in instrumental contingency degradation tasks (Barfield and Gourley, 2019). Two to five independent dendritic segments per mouse were imaged and scored.

\section{Protein quantification}

Western blotting

Itgb1-flox mice were infused with Cre \pm -expressing viral vectors as described above and killed 3 weeks later. Separate 5- to 6-week-old mice were given three injections of vehicle or fasudil as described above, a minimal amount that can trigger dendritic spine plasticity (Shapiro et al., 2019), and then killed $1 \mathrm{~h}$ after the last injection. In both cases, mice were briefly anesthetized by isoflurane and decapitated. Brains were rapidly extracted and frozen at $-80^{\circ} \mathrm{C}$ and then sectioned into 1 -mm-thick sections. A $1 \mathrm{~mm}$ tissue core was used to extract 2 punches per mouse, which were treated as independent samples to conserve animal usage.

Tissue punches were homogenized by sonication in lysis buffer [100$200 \mu \mathrm{l}: 137 \mathrm{~mm} \mathrm{NaCl}, 20 \mathrm{~mm}$ Tris-HCl, pH 8, 1\% igepal, 10\% glycerol, 1:100 Phosphatase Inhibitor Cocktails 2 and 3 (Sigma Millipore), 1:1000 Protease Inhibitory Cocktail (Sigma Millipore)]. Protein concentrations were determined by Bradford colorimetric assay (Pierce), and $50 \mu \mathrm{g} /$ sample (for $\beta 1$-integrin) or $15 \mu \mathrm{g} / \mathrm{sample}$ (for others) was separated by SDS-PAGE on a $12 \%$ gradient Tris-glycine gel (Bio-Rad). Following transfer to PVDF membrane, membranes were blocked with 5\% nonfat milk.

Primary antibodies were anti-CD29 ( $\beta$ 1-integrin; BD Transduction Laboratories; Ms; 1:50), GluAl (C terminal sequence; Abcam; Rb; 1:1000), ROCK2 (Abcam; Rb; 1:1000), phosphorylated (p-) ROCK2ser1366 (GeneTex; Rb; 1:500), and tropomyosin receptor kinase B (trkB; Cell Signaling; Rb; 1:1000). Anti-HSP-70 (Santa Cruz Biotechnology; Ms; 1:5000) served as a loading control and did not differ between groups. Immunoreactivity was assessed using a chemiluminescence substrate (Pierce) and measured using a ChemiDoc MP Imaging System (Bio-Rad). Densitometry values were normalized to the corresponding loading control. 
Immunostaining

Mice were infused with $P t k 2 b$-overexpressing viral vectors, as described above. Three weeks later, mice were deeply anesthetized with ketamine/ xylazine $(100 \mathrm{mg} / \mathrm{kg}, 10 \mathrm{mg} / \mathrm{kg}$, i.p.) and subject to intracardiac perfusion with chilled saline, and then $4 \%$ PFA. Brains were harvested and stored in $4 \%$ PFA for $48 \mathrm{~h}$ and then transferred to $30 \% \mathrm{w} / \mathrm{v}$ sucrose before being sectioned into $50 \mu \mathrm{m}$ sections. Sections were blocked in a PBS solution containing 2\% normal goat serum, $1 \%$ BSA, and $0.3 \%$ Triton X-100 (Sigma Millipore) for $1 \mathrm{~h}$ at room temperature. Sections were then incubated in primary antibody solution containing $0.3 \%$ normal goat serum, $1 \%$ BSA, and $0.3 \%$ Triton $\mathrm{X}-100$ at $4^{\circ} \mathrm{C}$ for $48 \mathrm{~h}$. Anti-Pyk2 (Cell Signaling Technology; Rb; 1:500) served as the primary antibody. Sections were incubated in secondary antibody solution containing $0.5 \%$ normal goat serum and $0.3 \%$ Triton X-100, with AlexaFluor-594 (Invitrogen; 1:400) serving as the secondary antibody. Sections were imaged on a Nikon 4550s SMZ18 microscope with settings held constant across samples. A ring with a radius of $130 \mu \mathrm{m}$ was placed at the infusion terminal, and fluorescence was quantified in National Institutes of Health ImageJ. Between 1 and 3 sections per mouse were imaged, depending on visibility of the infusions site, and each mouse contributed a single value (the mean of its values) to comparisons to avoid over-representation of any given animal.

\section{Statistical analyses}

Two-tailed statistical analyses were performed using SPSS 27 and SigmaPlot 11. Response rates were compared by ANOVA with repeated measures when appropriate. ANOVAs included groups, as well as active versus inactive ports, or degraded versus nondegraded conditions as factors. Post hoc comparisons were applied following interaction effects, and significant effects are indicated in the figures. Throughout, $p<0.05$ was considered significant.

Other comparisons were made by unpaired two-tailed $t$ tests: total cocaine infusions, dendritic spine densities, and Western blot and immunostaining density values. For protein quantifications, a small number of lanes appeared abnormal, suggesting aberrantly high values. They created values $>2$ SDs outside of the mean, resulting in the exclusion of 1 control and 2 fasudil values from the p-ROCK2 quantification and 1 control value in the Pyk2 quantification (Aguinis et al., 2013). Sessions required to reach response acquisition criterion in Figure $1 A$ were not normally distributed and compared between groups by a MannWhitney Rank Sum test. Cohen's $d$ values were used to calculate effect sizes. Group sizes are reported in the figure legends, along with the number of mice excluded because of viral vector misplacement (if any).

\section{Results}

Cocaine self-administration causes dendritic spine loss in the vlOFC

Addictive drugs modify dendritic spine densities and morphologies throughout the brain. One challenge, however, has been identifying links between structural changes and behavior, if any. We initiated these experiments by confirming that cocaine selfadministration causes dendritic spine loss in the vlOFC of mice, as in rats (Radley et al., 2015). Mice were briefly "pretrained" with food to familiarize them with nose poking; then intravenous catheters were placed for cocaine delivery. Following recovery, mice were trained to respond for cocaine in separate chambers; a comparator group of mice responded for food. When mice reached maintenance criteria, training was discontinued. Here, they reached maintenance criteria within 5-13 sessions, so the associated graph represents the final 5 sessions for each mouse (Fig. 1A). Including the pretraining period, cocaine-reinforced mice received on average $9.2( \pm 0.83$ SEM) training sessions, and food-reinforced mice received 9 ( \pm 0.0 SEM) sessions (MannWhitney $U=14.5, p=0.45$; not shown).

Notably, food-reinforced response rates were higher than cocaine-reinforced response rates (left vs right axes; Fig. 1A), similar to seminal experiments comparing the effects of sucrose and amphetamine self-administration on dendritic spine densities in the OFC (Crombag et al., 2005). We nevertheless felt that a food-reinforced comparator group was important, as opposed to saline-infused mice that would generate minimal instrumental behavior.

We killed mice 2 weeks following the last day of training (timeline in Fig. 1A). Cocaine self-administering mice had 14.5\% fewer dendritic spines on excitatory vlOFC neurons (unpaired $t_{(12)}=-2.3, p=0.04, d=-1.36$; Fig. $\left.1 B\right)$, comparable to $\sim 17 \%$ loss in cocaine self-administering rats (Radley et al., 2015). We did not identify obvious differences between dendritic spine subtypes (i.e., no particular subtype was affected more than any other; not shown), also in agreement with prior experiments in rats (Radley et al., 2015).

\section{The cell adhesion factor $\beta 1$-integrin confers resilience to cue- induced reinstatement of cocaine seeking}

To destabilize dendritic spines on excitatory neurons of cocainenaive mice, we next reduced $\operatorname{Itg} b 1$, which encodes $\beta 1$-integrin, by infusing AAV-mCherry-Cre in the vlOFC of Itgb1-flox mice. Figure $1 C$ provides a timeline and summarizes infusion sites throughout this report; some spread into the medial OFC was detected in a minority of mice and was without obvious consequence. If infusions spared the vlOFC, mice were excluded.

Viral-mediated gene knockdown reduced $\beta 1$-integrin levels by $\sim 30 \%$ in bulk vlOFC tissue punches (unpaired $t_{(36)}=2.4$, $p=0.03, d=-0.76$; Fig. $1 D$ ). Modest protein loss was expected, given that tissue punches contained both transfected and unaffected cells. To verify dendritic spine loss, we enumerated dendritic spines on mCherry-expressing neurons \pm Cre in the vlOFC. Itgb1 knockdown reduced dendritic spine densities as expected (unpaired $t_{(14)}=2.7, p=0.02, d=1.35$; Fig. $1 E$ ).

We next tested behavioral consequences. A new cohort of Itgb1 knockdown mice acquired cocaine-reinforced nose poke responses, without differences between groups (main effect of session $F_{(9,99)}=2.4, p=0.015$; no main effect of group or group $\times$ session interaction $F$ values $<1$; Fig. $1 F$ ). A session $\times$ port interaction indicated that the mice differentiated between the "active" and "inactive" responses over time, referring to responses that were and were not reinforced $\left(F_{(1,99)}=4.9, p=0.049\right.$; Fig. $\left.1 F\right)$. Groups ultimately ingested equivalent amounts of cocaine (unpaired $t_{(11)}=$ $-1.5, p=0.41$; Fig. $1 G)$. We then initiated extinction conditioning, in which case, responding was not reinforced, and cocaine-associated cues were not present. Groups again did not differ (main effect of session $F_{(4,40)}=53.9, p<0.001$; no other main effects or interactions $F$ values $<1$; Fig. $1 H$ ).

Next, we assessed cue-induced reinstatement of cocaine seeking, referring to responding that is energized by the presentation of cocaine-associated cues, even despite prior extinction. Both groups exhibited reinstatement, but knockdown mice generated nearly twice as many responses as control mice (main effect of reinstatement vs last day of extinction $F_{(1,10)}=54.2, p<0.001$; group $\times$ session interaction $F_{(1,10)}=6.7, p=0.03$; main effect of group $F_{(1,10)}=5.9, p=0.04$; reinstatement session $d=-1.47$; Fig. 1I). This experiment indicates that reducing Itgb1 exacerbated cocaine-seeking behavior following extinction. Here, we waited 2 weeks between the last day of extinction training and the reinstatement test. Our goal was to match the timing of the dendritic spine imaging experiments above, but notably, the use of this washout period raises the possibility that dendritic spine stability 
in the vlOFC particularly mitigates the spontaneous recovery of cocaine-seeking behavior or incubated cocaine-seeking behavior.

\section{The cell adhesion factor $\beta 1$-integrin is necessary for integrating new information into established behaviors}

A view of OFC function is that it integrates new information into familiar behaviors to modify those behaviors when appropriate (Stalnaker et al., 2015). The experiment described above could be interpreted as evidence that $\beta 1$-integrin-mediated dendritic spine stability enables mice to integrate new information (in this case, learned during extinction) into future response strategies, resulting in aberrantly high response rates in the absence of Itgb1 in the reinstatement test. We pursued this possibility using food-reinforced tests.

We first reduced Itgb1 in the vlOFC of mice and then delivered food in the presence of a sustained light, creating a context in which food was available. No behaviors were explicitly reinforced. Another sustained light signaled a period when no food was available. Mice experienced both conditions every day in random order (Fig. $2 A$ ). With time, mice entered the food magazine more during the food-predictive light (the $\mathrm{CS}^{+}$) than the light that did not predict food (the $\mathrm{CS}^{-}$) (main effect of CS $F_{(1,13)}$ $=66.1, p<0.001 ; \mathrm{CS} \times$ session interaction $F_{(6,78)}=6.5$, $p<0.001$; no main effect of group $F<1$; no 3-factor interaction $F_{(1,13)}=2.5, p=0.14$; Fig. $\left.2 B\right)$. This pattern indicates that the mice could discriminate between the conditions that were and were not predictive of food.

CS discrimination was further confirmed in a group of mice that were next presented with brief alternating CS's within the same session. Both groups again discriminated between the CS's, entering the food magazine more during the $\mathrm{CS}^{+}$than $\mathrm{CS}^{-}$ (main effect of CS $F_{(1,11)}=15.19, p=0.002$; no CS $\times$ group interaction $F<1$; Fig. $2 C$ ). Knockdown mice also generated modestly higher magazine entry rates overall (main effect of group $F_{(1,11)}=$ 7.52, $p=0.02$; Fig. $2 C$ ).

Mice were next trained to press a previously recessed lever for the same food. Light cues were not present. Mice differentiated between reinforced and nonreinforced behaviors, pressing the lever more than poking inactive nose poke ports. Again, groups did not differ (main effect of lever-press vs nose-poke $F_{(1,13)}=$ $36.5, p<0.001$; response $\times$ session interaction $F_{(5,65)}=10.1$, $p<0.001$; no main effect of group $F<1$; no other interaction effects, $F$ values $<1$; Fig. $2 D$ ).

Finally, the $\mathrm{CS}^{+}$was presented for the first time in the presence of the lever. We hypothesized that control mice would increase responding because of the overlay of Pavlovian and instrumental control over action, similar to the Pavlovian-toinstrumental transfer phenomenon (Cartoni et al., 2016). If $\beta 1$ integrins are important for integrating new information into familiar routines, then response rates would remain static in the knockdown mice. The $\mathrm{CS}^{+}$energized lever-pressing, as expected (main effect of testing phase $F_{(2,26)}=3.8, p=0.036$; Fig. $2 E$, top). However, a testing phase $\times$ group interaction also indicated that the groups differed in their response patterns $\left(F_{(2,26)}=4.0\right.$, $p=0.031$; Fig. $2 E$, top). In the control group, response rates were higher during the $\mathrm{CS}^{+}$period than when no cues were present, as expected. By contrast, in the knockdown mice, response rates were variable and ultimately not different between testing phases. The key interaction effect was detectable even when the final day of training was excluded from the ANOVA (testing phase $\times$ group $F_{(1,13)}=10.6, p=0.006$; no other effects, $F$ values $<1$; Fig. $2 E$, bottom), evidence of its robustness.
This pattern suggests that $\beta 1$-integrins in the vlOFC are necessary for incorporating new information into existing response strategies. Another way to test this capacity is to modify the likelihood that a familiar behavior will be rewarded. A new cohort of Itgbl knockdown mice was first trained to nose poke at two ports for food in the absence of discrete Pavlovian stimuli (Fig. 2F). Response rates on both ports are collapsed for simplicity, and groups did not differ in response acquisition (main effect of session $F_{(4,76)}=14.7, p<0.001$; no other main effects or interactions $F$ values $<1$; Fig. $2 G)$.

Next, one action ceased to be reinforced, causing control mice to inhibit that action accordingly (Fig. 2H). Meanwhile, knockdown mice were insensitive to changing contingencies and continued to generate both responses equally (main effect of response option $F_{(1,19)}=14.2, p<0.001$; response option $\times$ group interaction $F_{(1,19)}=14.2, p<0.001$; no main effect of group $F<1$; post hoc control $d=1.50$; knockdown $d=0.00$; Fig. $2 H)$. Thus, the cell adhesion factor $\beta 1$-integrin in the vlOFC appears necessary for mice to integrate new information into existing response strategies. The rest of our investigation used this task to identify likely intracellular and anatomic signaling partners.

\section{A cell adhesion signaling axis in the vlOFC supports action updating}

We first attempted to correct action updating in knockdown mice by pharmacologically recapitulating intracellular signaling that would otherwise be triggered by neuronal $\beta 1$-integrin activation. Positive outcomes would delineate a $\beta 1$-integrin-mediated signaling axis that likely controls vlOFC function.

One consequence of neuronal $\beta 1$-integrin activation is the inhibition of ROCK, particularly the neuronally enriched ROCK2 isoform (Fig. $3 A$ ). Thus, we first tested fasudil, a smallmolecule inhibitor active at the ATP binding site of ROCK. ROCK is not activated by phosphorylation, but phosphorylation at ser1366 tightly correlates with ROCK2 activation status (Chuang et al., 2012). Therefore, we validated our systemic dose of fasudil by quantifying p-ROCK2-ser1366 in the vlOFC, as well as AMPAR GluA1, given that ROCK inhibitors can decrease their levels (Ota et al., 2010). A main effect of fasudil (vs vehicle) indicated that our chosen dose reduced protein levels as expected $\left(F_{(1,47)}=8.7, p=0.005\right.$; no other effects $F$ values $<1$; p-ROCK2ser1366 $d=0.69$; GluA1 $d=0.95$; Fig. $3 B$ ). To confirm that fasudil did not generally suppress protein levels, we next immunoblotted for trkB, which is elevated by ROCK inhibition in the mPFC (Shapiro et al., 2019). Fasudil increased vlOFC levels, as expected (unpaired $t_{(38)}=-2.3, p=0.03, d=-0.74$; Fig. $3 B$ ).

In behavioral tests, fasudil did not impact instrumental response acquisition (main effect of session $F_{(4,104)}=38.3$, $p<0.001$; no other main effects or interactions $F$ values $<1$; Fig. $3 C)$. Itgb1 silencing blocked response updating when one familiar behavior ceased to be reinforced, as expected, but ROCK inhibition restored this ability (main effect of response option $F_{(1,26)}$ $=31.3, p<0.001$; 3 -factor response option $\times$ fasudil $\times$ knockdown interaction $F_{(1,26)}=5.2, p=0.03$; no other main effects or interactions $F$ values $<1$; post hoc control $d=1.67$; fasudil alone $d=1.15 ;$ knockdown alone $d=0.00 ;$ fasudil + knockdown $d=1.26$; Fig. $3 D$ ).

Arg kinase is an intermediary by which $\beta 1$-integrin activation inhibits ROCK (Kerrisk and Koleske, 2013) (again, Fig. 3A), leading to the prediction that activating Arg kinase should also restore response flexibility following Itgbl silencing. We administered a small-molecule Arg kinase activator, termed "DPH," at 

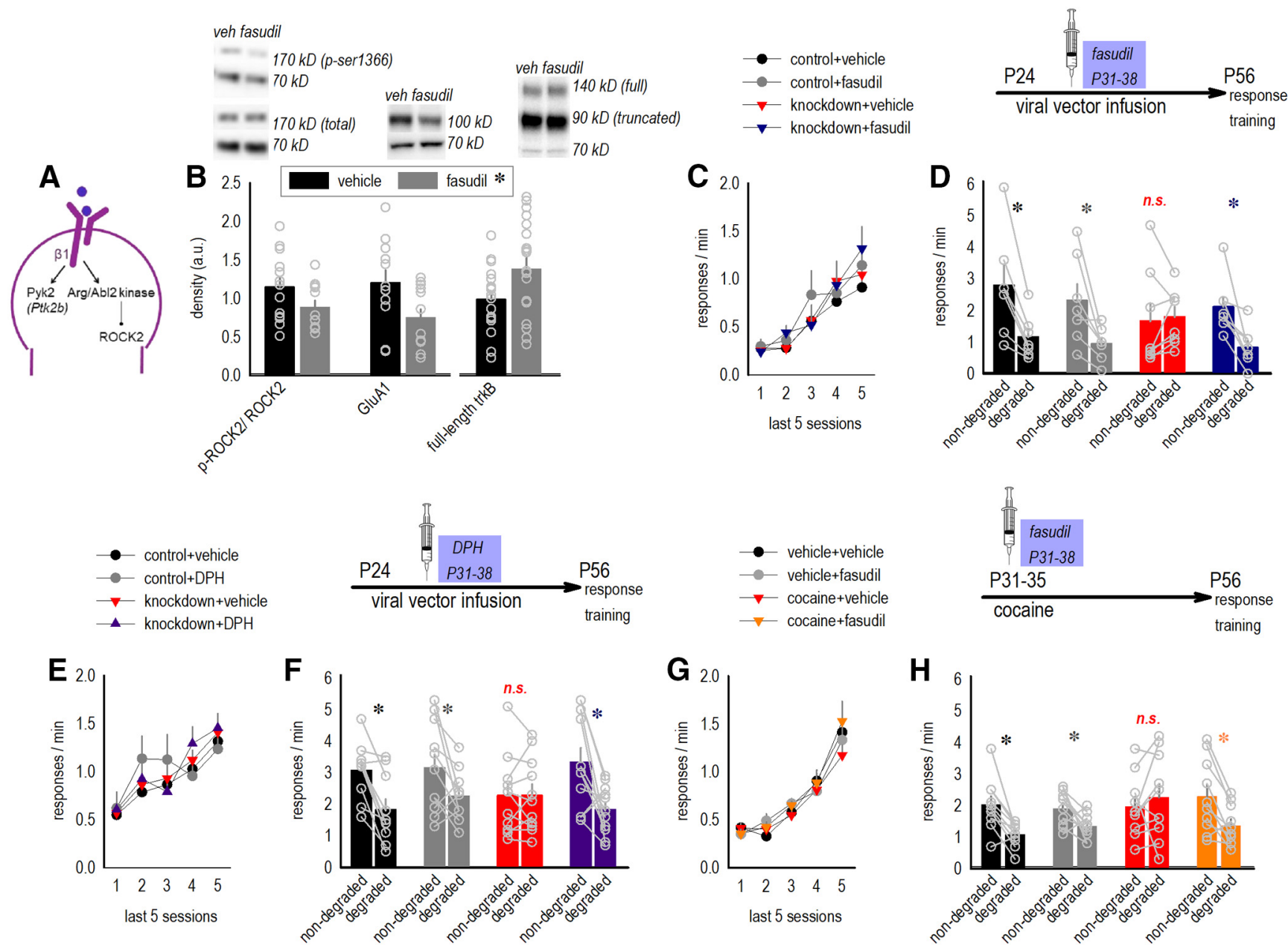

Figure 3. A $\beta$ 1-integrin-mediated signaling axis supports action updating. $A$, Schematic of $\beta 1$-integrin-mediated signaling events relevant to this and the next figure. $\beta 1$-integrins activate Ab12/Arg kinase, which can ultimately cause the inhibition of ROCK, particularly the ROCK2 isoform. Pyk2, encoded by Ptk2b, is also activated. $\boldsymbol{B}$, The ROCK inhibitor fasudil was administered intraperitoneally, reducing cortical p-ROCK2 and GluA1 and increasing trkB. Top, Representative blots with an HSP-70 loading control. C, Itgb1 knockdown mice were treated with fasudil. Groups did not differ during subsequent response training periods. $\boldsymbol{D}$, Knockdown mice failed to generate response preferences when one action ceased to be reinforced. The ROCK inhibitor corrected response updating ( $n=7$ control viral vector groups, $n=8$ knockdown groups). $\boldsymbol{E}$, Separate Itgb 1 knockdown mice were treated with the Arg kinase activator, DPH. Groups did not differ during response acquisition. $\boldsymbol{F}$, Knockdown mice failed to generate response preferences when one action ceased to be reinforced. The Arg kinase activator corrected response updating $(n=10$ control, $n=11$ all others; 6 mice with misplaced viral vectors were excluded). Vehicle-treated mice are the same as in Figure 2. G, We then applied the ROCK inhibitor to cocaine-treated mice. Groups did not differ in response acquisition. $\boldsymbol{H}$, Cocaine caused response updating failures, and ROCK inhibition recovered response preferences $(n=10 /$ group). Closed symbols and bars represent mean + SEM. ${ }^{*} p<0.05$. Open symbols represent individual mice. Experiments were conducted twice. All groups were included in each replicate, and both replications are represented here.

a dose that stimulates Arg kinase in the brain (Shapiro et al., 2017b). Groups did not differ when initially trained to nose poke (main effect of session $F_{(4,156)}=24.5, p<0.001$; no other main effects or interactions $F$ values $<1$; Fig. 3E). Itgb1 knockdown blocked response updating, as expected, but activation of Arg kinase restored it (main effect of response option $F_{(1,39)}=26.4$, $p<0.001$; 3 -factor response option $\times \mathrm{DPH} \times$ knockdown interaction $F_{(1,39)}=4.6, p=0.01$; no other main effects or interactions $F$ values $<1$; post hoc control $d=1.50$; DPH alone $d=0.69$; knockdown alone $d=-0.14$; DPH + knockdown $d=0.95$; Fig. $3 F$ ).

\section{Restoration of response updating following cocaine}

We next aimed to capitalize on these findings and improve response updating in cocaine-exposed mice. We exposed young mice to cocaine, given that individuals who initiate drug use during adolescence are less likely to seek treatment than individuals who initiate use in adulthood (Kessler et al., 2001). We administered the ROCK inhibitor as above. Groups did not differ in subsequent response acquisition (main effect of session $F_{(4,144)}=$ 97.4, $p<0.001$; no session $\times$ cocaine $\times$ fasudil interaction $F_{(4,144)}=1.8, p=0.13$; no other main effects or interactions $F$ values $<1$; Fig. $3 G$ ). Nevertheless, cocaine caused failures in response updating when one familiar behavior ceased to be reinforced, as expected (compare DePoy et al., 2017); meanwhile, ROCK inhibition restored response flexibility (main effect of response option $F_{(1,36)}=15.8, p<0.001 ; 3$-factor response option $\times$ fasudil $\times$ cocaine interaction $F_{(1,36)}=8.6, p=0.006$; no response option $\times$ fasudil interaction $F_{(1,36)}=2.4$, $p=0.13$; no response option $\times$ cocaine interaction $F_{(1,36)}=$ 2.7, $p=0.11$; no main effect of fasudil $F<1$; no main effect of cocaine $F_{(1,36)}=2.7, p=0.11$; post hoc control $d=1.33$; fasudil alone $d=0.80$; cocaine alone $d=-0.26$; fasudil + cocaine $d=1.17$; Fig. $3 H$ ).

We next stimulated a more immediate $\beta 1$-integrin signaling partner, Pyk2. It is closely related to focal adhesion kinase (FAK), and is even referred to as FAK2, but it is more highly concentrated at postsynaptic densities than FAK (Huang et al., 


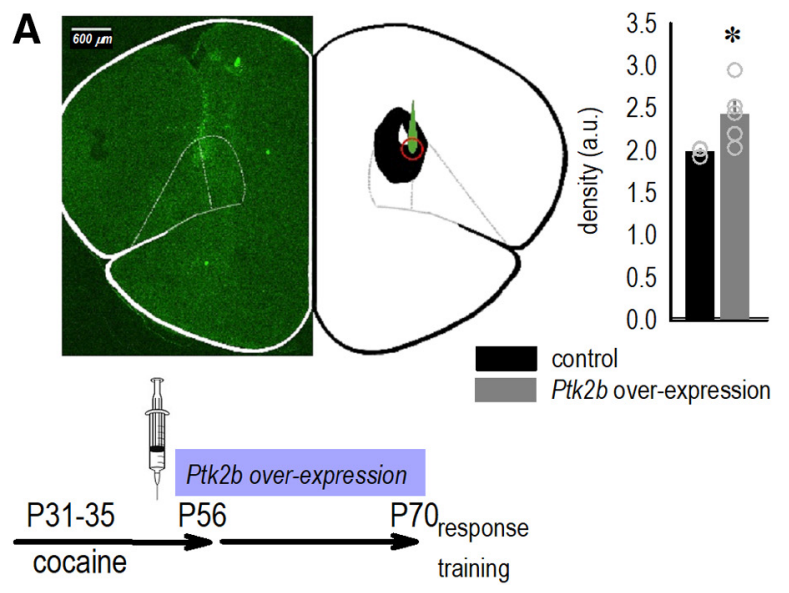

- control+vehicle $\quad$ - control+cocaine

- Ptk2b over-expression $\quad$ Ptk2b over-expression+cocaine
B

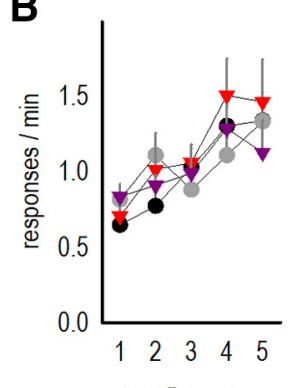

C

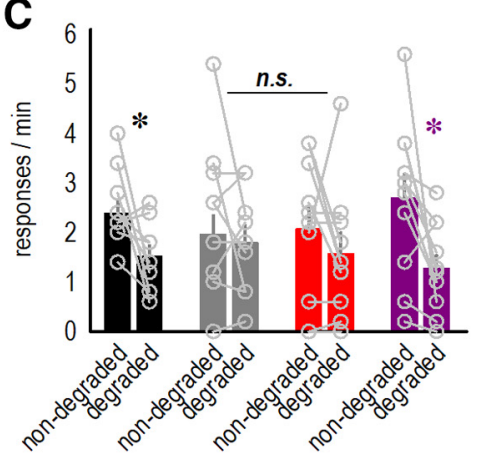

Figure 4. $\quad P t k 2 b$ overexpression restores action updating capacity following cocaine. $\boldsymbol{A}$, We overexpressed $P t k 2 b$ in the vIOFC, and measured Pyk2 protein in a ring centered at the base of the infusion site. Left, Representative Pyk2 label (green puncta). Right, Black represents the largest viral vector spread; white represents the smallest. Green image reflects a representative infusion site and is offset for clarity. Red ring represents the quantification zone. Graph represents viral-mediated Ptk2b overexpression increased Pyk2 ( $n=4$ control, $n=5$ overexpression). $\boldsymbol{B}$, Timeline: Separate mice were treated with cocaine, then infused with viral vectors. Groups did not differ in response acquisition. $\boldsymbol{C}$, Cocaine caused response updating failures, and $P t k 2 b$ overexpression recovered response preferences in cocaine-exposed mice ( $n=9$ control viral vector + vehicle, $n=10$ Ptk $2 b$ overexpression + vehicle, $n=10$ control viral vector + cocaine, $n=11$ Ptk2b overexpression + cocaine; 4 mice with misplaced viral vectors were excluded). (losed symbols and bars represent mean + SEM. ${ }^{*} p<0.05$. Open symbols represent individual mice. Immunostaining experiments were conducted in duplicate. Behavioral experiments were conducted in triplicate; all groups were included and are represented here.

2001). And unlike FAK, cortical levels of Pyk2 do not drop as animals mature (Menegon et al., 1999). This observation led us to stimulate Pyk2 after cocaine exposure, believing this strategy to be translational in nature, given that individuals seek treatment for drug misuse following a period of drug exposure.

Lacking selective activators, we used viral vectors to overexpress Ptk2b, which encodes Pyk2 (Fig. 4A). Quantification of Pyk2 at the viral vector infusion site confirmed that $P t k 2 b$ overexpression increased Pyk2 levels (unpaired $t_{(7)}=2.4, p=0.047$, $d=1.62$; Fig. $4 A$ ). Upregulation was modest, which was expected given that Pyk2 is endogenously highly expressed in microglia (Zhang et al., 2014).

In behavioral experiments, groups did not differ in response acquisition (main effect of session $F_{(4,144)}=13.9, p<0.001$; no main effects of virus or cocaine $F$ values $<1$; no session $\times$ cocaine interaction $F<1$; no session $\times P t k 2 b$ interaction $F_{(4,144)}=$
1.6, $p=0.18$; no session $\times$ cocaine $\times P t k 2 b$ interaction $F<1$; Fig. 4B). Cocaine-exposed mice were unable to modify response strategies when contingencies changed, as before, while $P t k 2 b$ overexpression restored response flexibility (main effect of response option $F_{(1,36)}=14.1, p<0.001 ; 3$ factor response option $\times P t k 2 b \times$ cocaine interaction $F_{(1,36)}=$ $4.1, p=0.05$; no other main effects or interactions, all $F$ values $<1$; post hoc control $d=0.87$; Ptk2b alone $d=0.40$; cocaine alone $d=0.36$; Ptk $2 b+$ cocaine $d=0.88$; Fig. $4 C)$. Interestingly, $P t k 2 b$ overexpression in cocaine-naive mice interfered with response updating, a finding addressed in Discussion.

The cell adhesion factor $\beta 1$-integrin is necessary for corticoamygdala-dependent action updating

Our findings reveal $\beta 1$-integrin signaling partners that appear to regulate vlOFC function. As cell adhesion factors, what anatomic connections might $\beta 1$-integrins support? BLA lesions alter the coding properties of OFC neurons (Schoenbaum et al., 2003), and BLA-to-OFC projections are essential for reversal tasks canonically considered OFC-dependent (Groman et al., 2019). BLAto-vlOFC projections are organized overwhelmingly ipsilaterally, meaning, the left vlOFC is largely connected with the left BLA and the right with the right (Murphy and Deutch, 2018). We took advantage of this segregated connectivity to use a modified "disconnection" design in which we silenced Itgb1 in one hemisphere's vlOFC and placed Gi-coupled DREADDs in the contralateral or ipsilateral BLA of the same mice (Fig. 5A-E). When infusions are contralateral (also called "asymmetric"), a healthy BLA is projecting to an Itgb1-deficient vlOFC, and in the contralateral hemisphere, the healthy vlOFC is connected with an inactivated BLA when the DREADD ligand $\mathrm{CNO}$ is on-board (Fig. $5 A$ ). If $\beta 1$-integrins support BLA-to-vlOFC connections, then the contralateral condition will recapitulate the behavioral effects of bilateral Itgb1 silencing. Meanwhile, the ipsilateral infusions will leave one BLA-to-vlOFC connection intact (Fig. 5A).

We delivered the DREADD ligand CNO immediately following the training session when familiar action-outcome associations are violated (Fig. 5F), when vlOFC activity is necessary for expectancy updating (Zimmermann et al., 2017, 2018; Whyte et al., 2019). We then tested response preference the next day when mice were drug-free.

The experiment included intact control mice, mice bearing control viral vectors (ipsilateral or contralateral), and ipsilateral and contralateral experimental groups. Groups did not differ in response acquisition (main effect of session $F_{(4,100)}=6.8$, $p<0.001$; no interactions $F$ values $<1$; no effect of group $F_{(3,25)}=2.0, p=0.15$; Fig. $\left.5 F\right)$. When a familiar contingency was violated, mice overwhelmingly preferred the behavior that remained reinforced, with the notable exception of the contralateral group, which did not display a systematic response preference (main effect of response option $F_{(1,25)}=13.0, p=0.001$; response option $\times$ group interaction $F_{(3,25)}=4.1, p=0.02$; no main effect of group $F<1$; post hoc intact control $d=1.18$; control viral vector $d=0.92$; ipsilateral $d=2.51$; contralateral $d=$ -0.33 ; Fig. $5 G)$. Thus, $\beta 1$-integrins in the vlOFC appear necessary for BLA-dependent response updating.

\section{$\beta 1$-integrins in the vlOFC are not obviously necessary for} cortico-striatal-dependent action updating

Given that $\beta 1$-integrins are considered largely postsynaptic, we anticipated that the same "disconnection" would have no effect if DREADDs were placed in a region that does not project to the 

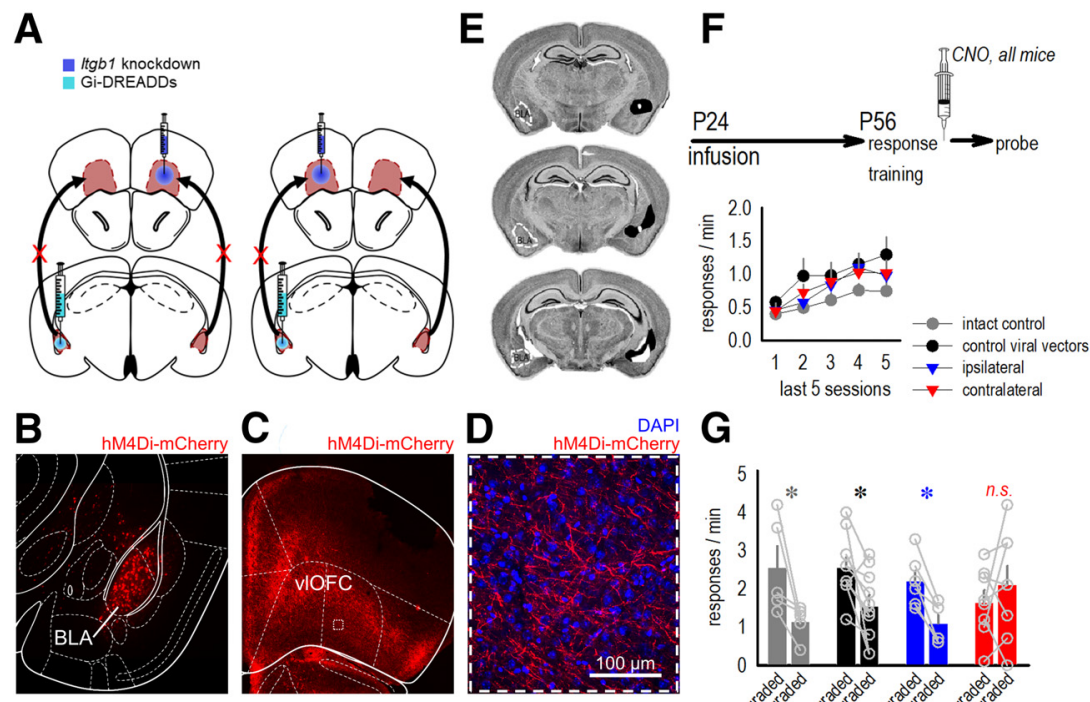

G

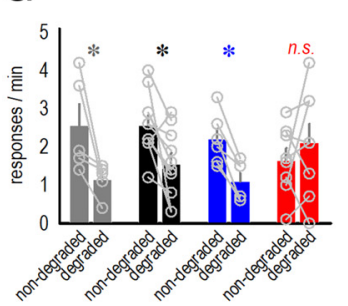

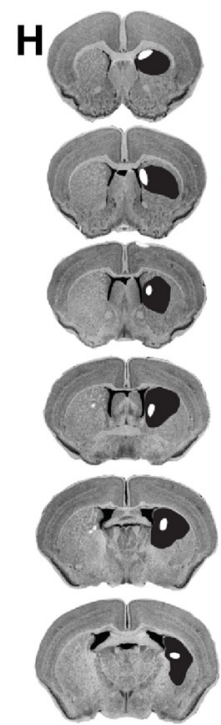

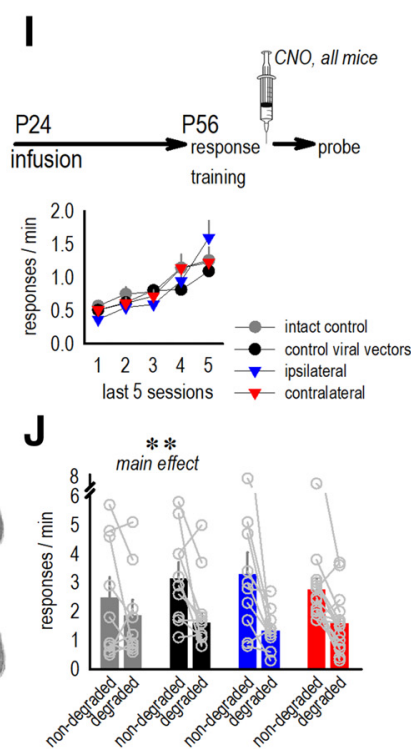

Figure 5. $\quad \beta$ 1-integrins in the vIOFC are necessary for cortico-amygdala-dependent action. $\boldsymbol{A}$, Experimental design: Mice were infused unilaterally with control viral vectors or CaMKII-driven hM4Di-DREADD in the BLA and control viral vectors or Cre in the vIOFC. Hemispheres were counterbalanced. When infusions were contralateral, both intrahemispheric connections were affected (left). When infusions were ipsilateral, one intrahemispheric connection was unaffected, and the other was spared (right). If $\beta 1$-integrins in the vlOFC sustain sensitivity to BLA inputs, then contralateral infusions will occlude behavioral response updating. $\boldsymbol{B}$, Representative BLA infusions, with $(\boldsymbol{C})$ amygdala-derived fluorescence in a coronal cortical section. BLA terminals were broadly distributed, as previously reported (Kita and Kitai, 1990), and included the vIOFC. D, Terminals in the vIOFC are presented at high magnification. $\boldsymbol{E}$, Histologic representation of BLA infusions, with black representing the large infusions and white representing small infusions on coronal sections from the Mouse Brain Library (Rosen et al., 2000). $\boldsymbol{F}$, Timeline of experimental events, including the administration of the DREADD ligand CNO to all mice, regardless of viral vector expression. Groups did not differ in response acquisition. $\mathbf{G}$, All groups, except for the contralateral group, updated response preferences. This pattern suggests that $\beta 1$-integrins in the vlOFC are necessary for sensitivity to amygdalar inputs ( $n=5$ intact control, $n=10$ control viral vector, $n=6$ ipsilateral, $n=8$ contralateral; 2 mice with misplaced viral vectors were excluded.). $\boldsymbol{H}$, This experiment was recapitulated, except that DREADDs were infused into the DMS rather than BLA. Histologic representation of DMS infusions. Black represents the large infusions. White represents the small infusions on coronal sections from the Mouse Brain Library (Rosen et al., 2000). $I$, The experimental timeline was identical. Groups did not differ in response acquisition. J, Groups did not differ in their ability to update response strategies, indicated by a main effect of response option and lack of other effects ( $n=9$ intact control, $n=9$ control viral vector, $n=10$ ipsilateral, $n=15$ contralateral). Closed symbols and bars represent mean + SEM. ${ }^{*} p<0.05$. ${ }^{* *} p<0.001$. Open symbols represent individual mice. Experiments were conducted twice. All groups were included in each replicate, and both replications are represented here.

vlOFC. To test this possibility, we used the same procedure, except infusing the DREADD-expressing viral vector into the DMS (Fig. 5H,I). vlOFC-to-DMS projections are necessary for response flexibility when outcome values change (Gremel and Costa, 2013), but the DMS does not convey reciprocal connections to the vlOFC (e.g., see Schilman et al., 2008). In this case, we again identified no group effects in response acquisition (main effect of session $F_{(4,156)}=44.0, p<0.001$; no interaction $F=1$; no effect of group $F_{(3,39)}=1.7, p=0.19$; Fig. $\left.5 I\right)$. Despite considerable viral vector spread in the DMS extending well into the critical posterior regions necessary for goal-directed action (Yin et al., 2005), all groups were able to update response strategies when contingencies changed (main effect of response option $F_{(1,39)}=29.9, p<0.001$; no other main effects or interactions $F$ values $<1$; Fig. 5J). Thus, asymmetric Itgb1 knockdown in the vlOFC and DMS silencing did not impact the ability of mice to update response strategies.

\section{Discussion}

The OFC is thought to build "task spaces," referring to abstract representations of the associative and causal structures formed by task-relevant variables within an environment (Niv, 2019). As such, the OFC is necessary for behaviors that are dynamic, sensitive to changes in environmental circumstances and unexpected events. OFC function is degraded by addictive substances as drug-related cues occupy cognitive territory (Lucantonio et al., 2012; Everitt and Robbins, 2016). Psychostimulants cause dendritic spine loss on OFC neurons, detectable even when drug self-administering animals are compared with food self-administering counterparts (Crombag et al., 2005) (see Fig. 1), but identifying links between the structural and behavioral consequences of addictive drugs has been challenging. Here we destabilized dendritic spines on neurons in the vlOFC by reducing levels of the cell adhesion factor, $\beta 1$-integrin. Deficient mice were more prone to the reinstatement of cocaine seeking following extinction than control mice, and they deferred to familiar behavioral sequences in food-reinforced tasks, resembling habitual action in cocaine-using humans (Ersche et al., 2016) and rodents (Gourley and Taylor, 2016).

The response profiles of $\beta 1$-integrin-deficient mice could be viewed as failures in integrating new information into future response strategies. To assess this possibility, we created a procedure in which a sustained light was associated with food, setting a food delivery context, and then mice were trained separately to lever-press for the same food. Later, the light and lever were presented simultaneously. Control mice energized responding when the light was present, presumably because of association with reward. Meanwhile, $\beta 1$-integrin-deficient mice did not systematically modify their response strategies. vlOFC lesions also induce response stasis in conceptually similar Pavlovian-toinstrumental transfer tasks (Balleine et al., 2011). We suggest that $\beta 1$-integrins are a key mechanism by which the vlOFC promotes instrumental response updating when behavioral plasticity is adaptive.

We next turned to a task in which mice were trained to generate two instrumental responses for food pellets, initially delivered with equal probability. Then, the relationship between one action 
and its outcome was weakened when responding ceased to be reinforced. Control mice directed their energies toward the contingency that remained intact, whereas knockdown mice did not. Thus, $\beta 1$-integrin-mediated dendritic spine stabilization again appears necessary for vlOFC function, specifically in incorporating new information about the causal efficacy of actions into future choice (Zimmermann et al., 2017, 2018; Parkes et al., 2018; Fresno et al., 2019).

Importantly, $\beta 1$-integrin-deficient mice were able to acquire cocaine- and food-reinforced responses and discriminate between lights that were and were not predictive of food, consistent with abundant evidence that the OFC is involved in modifying familiar behaviors, but not initially learning them (Stalnaker et al., 2015). Also notable, we surprisingly did not detect effects of $\beta 1$-integrins on instrumental response extinction, although extinction requires response updating. Our extinction sessions were long and entirely lacking in cocaine or reinforcement-associated stimuli; thus, we think it likely that our procedure was simply too blunt an instrument to reveal influences of $\beta 1$-integrins, if any. Orbitofrontal cortical BDNF, whose high-affinity receptor is transactivated by $\beta 1$-integrins (Wang et al., 2016), is involved in extinction, but effects were identified using short time bins spread across multiple days (Gourley et al., 2009, 2013). If we had similarly parcellated response rates into shorter time bins here, we might have identified impacts of $\beta 1$ integrins.

\section{A cell adhesion signaling axis controls OFC function}

How might $\beta$ 1-integrins control vlOFC function? Arg kinase is a neuronal $\beta 1$-integrin substrate that stabilizes postnatal dendrites and dendritic spines (Kerrisk and Koleske, 2013). OFC levels of the Arg substrate p190RhoGAP increase during early postnatal life, potentially a signal by which certain dendritic spines escape pruning during this period (Shapiro et al., 2017a). We administered a small-molecule Arg activator, which corrected response biases in $\beta 1$-integrin-deficient mice. This pattern suggests that $\beta 1$-integrin-Arg activity optimizes vlOFC function.

$\beta 1$-integrin-Arg activation inhibits the RhoA GTPase substrate ROCK (Kerrisk and Koleske, 2013). ROCK otherwise inhibits cofilin-mediated actin cycling and can thereby prevent changes in dendritic spine morphology (Maekawa et al., 1999; Zhou et al., 2009). Meanwhile, ROCK inhibition can promote activity-dependent dendritic spine pruning or spine head enlargement (stabilization), depending on the extracellular milieu (Schubert et al., 2006; Murakoshi et al., 2011), multifaceted properties likely attributable in part to distinct ROCK1/2 isoforms (Newell-Litwa et al., 2015). As with Arg activation, a ROCK inhibitor (active at both isoforms) restored response flexibility in $\beta 1$-integrin-deficient mice, suggesting that a $\beta 1$-integrin-ArgROCK axis supports vlOFC function.

Our chosen ROCK inhibitor, fasudil, is clinically used to treat certain forms of stroke and has oral bioavailability and minimal side effects (Chen et al., 2013). We thus translated the same treatment to mice exposed to cocaine, in which case, inhibiting ROCK blocked subsequent habit-like response biases. Cocaineinduced response biases are likely attributable to multiple factors, including poor instrumental learning (DePoy et al., 2014; Lim et al., 2019) and deliberative-like behavior (Sweis et al., 2018), and potentially slowed reaction time with vlOFC damage (Hardung et al., 2017). Notably, our ROCK inhibitor was administered before behavioral testing. Previously, we instead paired it with behavioral training to amplify learning-related dendritic spine plasticity (Swanson et al., 2017; Whyte et al., 2019). We suspect that ROCK inhibition had corrective effects here in part because it upregulates trkB, the high-affinity receptor for BDNF. trkB signaling within the vlOFC is necessary for mice to update dynamic goal-seeking action (Zimmermann et al., 2017; Pitts et al., 2018, 2020).

Finally, we overexpressed the integrin partner Pyk2, a FAK family member highly expressed in the mature cerebral cortex (Menegon et al., 1999) and concentrated at the postsynaptic density (Huang et al., 2001). We overexpressed $P t k 2 b$ within the vlOFC, recovering response flexibility following cocaine. We envision that increasing Pyk2 counters the structural destabilizing effects of cocaine by amplifying integrin-mediated signaling, given that: (1) Pyk2 stimulates neurite outgrowth downstream of growth factor and integrin receptor activation (Ivankovic-Dikic et al., 2000); (2) it is downstream of neuronal $\beta 1$-integrin-containing receptors (Bernard-Trifilo et al., 2005; Morini and Becchetti, 2010); and (3) it is involved in the support of LTP by synaptic $\beta 1$-integrins (Park and Goda, 2016). Notably, Pyk2 overexpression in cocaine-naive mice interfered with response updating. This pattern is consistent with evidence that vlOFC overactivation causes habit-like behavior (Hinton et al., 2019; Morisot et al., 2019), likely reflecting an inverted U-shaped function in vlOFC control over goal-sensitive action.

\section{Cell adhesion support of vlOFC-BLA interactions}

The BLA is necessary for integrating new outcome-related information into action strategies (Balleine et al., 2003), and its involvement in some tasks precedes that of the vlOFC, suggesting that the BLA conveys information to the vlOFC (Zimmermann et al., 2018). BLA-to-vlOFC projections are overwhelmingly ipsilateral (Murphy and Deutch, 2018), allowing us to use a functional "disconnection" strategy to determine whether $\beta 1$-integrins sustain sensitivity to BLA projections. We silenced Itgbl unilaterally in the vlOFC and delivered Gi-DREADDs to the contralateral BLA. In the presence of the DREADD ligand CNO, healthy BLA projections terminated on Itgb1-deficient vlOFC neurons in one hemisphere, whereas the BLA was inactive in the opposite hemisphere. These conditions blocked the ability of mice to update response preferences, suggesting that $\beta 1$-integrins anchor neurons within functional BLA-OFC networks. We envision that the BLA provides a signal to prioritize motivationally relevant behaviors that are likely to be reinforced in an ever-changing, uncertain environment (Wassum and Izquierdo, 2015; Manns and Bass, 2016). This signal is likely distinct from information about instrumental reward value, which requires OFC-to-BLA connections (Malvaez et al., 2019), but not BLA-to-OFC connections (Lichtenberg et al., 2017).

Notably, vlOFC damage reduces cue- and context-induced reinstatement of cocaine seeking, the opposite effect of Itgb1 knockdown here (Fuchs et al., 2004; Lasseter et al., 2009, 2011). One possibility is that dendritic spines on vlOFC neurons receiving inputs that promote drug seeking (e.g., from the piriform cortex) (Reiner et al., 2020) are distinct, and more able to control behavior when $\operatorname{Itg} b 1$ is lost. A challenge in future experiments will be to determine how vlOFC inputs are integrated and prioritized to ultimately impact the vlOFC outputs involved in goaldirected action (Gremel and Costa, 2013) and drug seeking (Arguello et al., 2017).

We anticipated that the same "disconnection" would have no effect if DREADDs were placed in a region that does not project 
to the vlOFC. Indeed, when DREADDs were in the DMS, response plasticity remained intact. Notably, our CaMKII-driven viral vectors would be expected to transfect medium spiny neurons in the DMS, which are enriched in CaMKII (Goto et al., 1994). Conceivably, silencing cholinergic interneurons might have had different consequences (reflecting the impact of Itgb1 on vlOFC output), since these cell populations are involved in "in-the-moment" response flexibility (Bradfield et al., 2013; Stalnaker et al., 2016).

In conclusion, repeated cocaine exposure causes dendritic spine loss in the OFC and alters reward-related action in a manner consistent with OFC damage (Lucantonio et al., 2012). Open questions concern which extracellular ligands adhere vlOFC neurons to the extracellular matrix. $\beta 1$-integrin-containing heterodimers recognize diverse ligands, but laminins and intercellular adhesion molecule- 5 are notable because they are abundant in the brain and regulate dendritic spines (Lilja and Ivaska, 2018), a possible focus in future investigations.

\section{References}

Aguinis H, Gottfredson RK, Joo H (2013) Best-practice recommendations for defining, identifying, and handling outliers. Org Res Methods 16:270301.

Arguello AA, Richardson BD, Hall JL, Wang R, Hodges MA, Mitchell MP, Stuber GD, Rossi DJ, Fuchs RA (2017) Role of a lateral orbital frontal cortex-basolateral amygdala circuit in cue-induced cocaine-seeking behavior. Neuropsychopharmacology 42:727-735.

Balleine BW, Killcross AS, Dickinson A (2003) The effect of lesions of the basolateral amygdala on instrumental conditioning. J Neurosci 23:666-675.

Balleine BW, Leung BK, Ostlund SB (2011) The orbitofrontal cortex, predicted value, and choice. Ann NY Acad Sci 1239:43-50.

Barfield ET, Gourley SL (2019) Glucocorticoid-sensitive ventral hippocampal-orbitofrontal cortical connections support goal-directed action: Curt Richter Award Paper 2019. Psychoneuroendocrinology 110:104436.

Barfield ET, Gerber KJ, Zimmermann KS, Ressler KJ, Parsons RG, Gourley SL (2017) Regulation of actions and habits by ventral hippocampal trkB and adolescent corticosteroid exposure. PLoS Biol 15:e2003000.

Barker JM, Torregrossa MM, Taylor JR (2013) Bidirectional modulation of infralimbic dopamine D1 and D2 receptor activity regulates flexible reward seeking. Front Neurosci 7:126.

Bernard-Trifilo JA, Kramar EA, Torp R, Lin CY, Pineda EA, Lynch G, Gall CM (2005) Integrin signaling cascades are operational in adult hippocampal synapses and modulate NMDA receptor physiology. J Neurochem 93:834-849.

Bradfield LA, Bertran-Gonzalez J, Chieng B, Balleine BE (2013) The thalamo-striatal pathways and cholinergic control of goal-directed action: interlacing new and existing learning in the striatum. Neuron 79:153166.

Cartoni E, Balleine B, Baldassarre G (2016) Appetitive pavlovian-instrumental transfer: a review. Neurosci Biobehav Rev 71:829-848.

Chen M, Liu A, Ouyang Y, Huang Y, Chao X, Pi R (2013) Fasudil and its analogs: a new powerful weapon in the long war against central nervous system disorders? Expert Opin Investig Drugs 22:537-550.

Chuang HH, Yang CH, Tsay YG, Hsu HY, Tseng LM, Chang ZF, Lee HH (2012) ROCKII ser1366 phosphorylation reflects the activation status. Biochem J 443:145-151.

Crombag HS, Gorny G, Li Y, Kolb B, Robinson TE (2005) Opposite effects of amphetamine self-administration experience on dendritic spines in the medial and orbital prefrontal cortex. Cereb Cortex 15:341-348.

DePoy LM, Gourley SL (2015) Synaptic cytoskeletal plasticity in the prefrontal cortex following psychostimulant exposure. Traffic 16:919-940.

DePoy LM, Perszyk RE, Zimmermann KS, Koleske AJ, Gourley SL (2014) Adolescent cocaine exposure simplifies orbitofrontal cortical dendritic arbors. Front Pharmacol 5:228.

DePoy LM, Zimmermann KS, Marvar PJ, Gourley SL (2017) Induction and blockade of adolescent cocaine-induced habits. Biol Psychiatry 81:595605 .
DePoy LM, Shapiro LP, Kietzman HW, Roman KM, Gourley SL (2019) $\beta 1$ integrins in the developing orbitofrontal cortex are necessary for expectancy updating. J Neurosci 39:6644-6655.

Ehrengruber MU, Hennou S, Büeler H, Naim HY, Déglon N, Lundstrom K (2001) Gene transfer into neurons from hippocampal slices: comparison of recombinant Semliki Forest Virus, adenovirus, adeno-associated virus, lentivirus, and measles virus. Mol Cell Neurosci 17:855-871.

Ersche KD, Gillan CM, Jones PS, Williams GB, Ward LH, Luijten M, de Wit S, Sahakian BJ, Bullmore ET, Robbins TW (2016) Carrots and sticks fail to change behavior in cocaine addiction. Science 352:1468-1471.

Everitt BJ, Robbins TW (2016) Drug addiction: updating actions to habits to compulsions ten years on. Annu Rev Psychol 67:23-50.

Feng G, Mellor RH, Bernstein M, Keller-Peck C, Nguyen QT, Wallace M, Nerbonne JM, Lichtman JW, Sanes JR (2000) Imaging neuronal subsets in transgenic mice expressing multiple spectral variants of GFP. Neuron 28:41-51.

Fuchs RA, Evans KA, Parker MP, See RE (2004) Differential involvement of orbitofrontal cortex subregions in conditioned cue-induced and cocaineprimed reinstatement of cocaine seeking in rats. J Neurosci 24:66006610.

Fresno V, Parkes SL, Faugere A, Coutureau E, Wolff M (2019) A thalamocortical circuit for updating action-outcome associations. eLife 8:e46187.

Garcia-Keller C, Neuhofer D, Bobadilla AC, Spencer S, Chioma VC, Monforton C, Kalivas PW (2019) Extracellular matrix signaling through $\beta 3$ integrin mediates cocaine cue-induced transient synaptic plasticity and relapse. Biol Psychiatry 86:377-387.

Gomez JL, Bonaventura J, Lesniak W, Mathews WB, Sysa-Shah P, Rodriguez LA, Ellis RJ, Richie CT, Harvey BK, Dannals RF, Pomper MG, Bonci A, Michaelides M (2017) Chemogenetics revealed: DREADD occupancy and activation via converted clozapine. Science 357:503-507.

Goto S, Yamada K, Oyama T, Korematsu K, Nagahiro S, Ushio Y, Fukunaga K, Miyamoto E, Hofer W (1994) Cellular localization of type II Ca ${ }^{2+}$ / calmodulin-dependent protein kinase in the rat basal ganglia and intrastriatal grafts derived from fetal striatal primordia, in comparison with that of $\mathrm{Ca}^{2+} /$ calmodulin-regulated protein phosphatase, calcineurin. Neuroscience 62:695-705.

Gourley SL, Taylor JR (2016) Going and stopping: dichotomies in behavioral control by the prefrontal cortex. Nat Neurosci 19:656-664.

Gourley SL, Howell JL, Rios M, DiLeone RJ, Taylor JR (2009) Prelimbic cortex bdnf knock-down reduces instrumental responding in extinction.. Learn Mem 16:756-760.

Gourley SL, Olevska A, Warren MS, Taylor JR, Koleske AJ (2012) Arg kinase regulates prefrontal dendritic spine refinement and cocaine-induced plasticity. J Neurosci 32:2314-2323.

Gourley SL, Olevska A, Zimmermann KS, Ressler KJ, Dileone RJ, Taylor JR (2013) The orbitofrontal cortex regulates outcome-based decision-making via the lateral striatum. Eur J Neurosci 38:2382-2388.

Gremel CM, Costa RM (2013) Orbitofrontal and striatal circuits dynamically encode the shift between goal-directed and habitual actions. Nat Commun 4:2264.

Groman SM, Keistler C, Keip AJ, Hammarlund E, DiLeon RJ, Pittenger C, Lee D, Taylor JR (2019) Orbitofrontal circuits control multiple reinforcement-learning processes. Neuron 103:734-746.

Hardung S, Epple R, Jackel Z, Eriksson D, Uran C, Senn V, Gibor L, Yizhar O, Diester I (2017) A functional gradient in the rodent prefrontal cortex supports behavioral inhibition. Curr Biol 27:549-555.

Hinton EA, Li DC, Allen AG, Gourley SL (2019) Social isolation in adolescence disrupts cortical development and goal-dependent decision making in adulthood, despite social reintegration. eNeuro 6:ENEURO.031819.2019.

Hinwood M, Tynan RJ, Charnley JL, Beynon SB, Day TA, Walker FR (2013) Chronic stress induced remodeling of the prefrontal cortex: structural reorganization of microglia and the inhibitor effect of minocycline. Cereb Cortex 23:1784-1797.

Huang Y, Lu W, Ali DW, Pelkey KA, Pitcher GM, Lu YM, Aoto H, Roder JC, Sasaki T, Salter MW, MacDonald JF (2001) CAKbeta/Pyk2 kinase is a signaling link for induction of long-term potentiation in CA1 hippocampus. Neuron 29:485-496.

Ivankovic-Dikic I, Grönroos E, Blaukat A, Barth BU, Dikic I (2000) Pyk2 and FAK regulate neurite out-growth induced by growth factors and integrins. Nat Cell Biol 2:574-581. 
Jackson SA, Horst NK, Pears A, Robbins TW, Roberts AC (2016) Role of the perigenual anterior cingulate and orbitofrontal cortex in contingency learning in the marmoset. Cereb Cortex 26:3273-3284.

Kerrisk ME, Koleske AJ (2013) Arg kinase signaling in dendrite and synapse stabilization pathways: memory, cocaine sensitivity, and stress. Int J Biochem Cell Biol 45:2496-2500.

Kessler RC, Aguilar-Gaxiola S, Berglund PA, Caraveo-Anduaga JJ, DeWit DJ, Greenfield SF, Kolody B, Olfson M, Vega WA (2001) Patterns and predictors of treatment seeking after onset of a substance use disorder. Arch Gen Psychiatry 58:1065-1071.

Kita H, Kitai ST (1990) Amygdaloid projections to the frontal cortex and the striatum in the rat. J Comp Neurol 298:40-49.

Lasseter HC, Ramirez DR, Xie X, Fuchs RA (2009) Involvement of the lateral orbitofrontal cortex in drug context-induced reinstatement of cocaineseeking behavior in rats. Eur J Neurosci 30:1370-1381.

Lasseter HC, Wells AM, Xie X, Fuchs RA (2011) Interaction of the basolateral amygdala and orbitofrontal cortex is critical for drug context-induced reinstatement of cocaine-seeking behavior in rats. Neuropsychopharmacology 36:711-720.

Lichtenberg NT, Pennington ZT, Holley SM, Greenfield VY, Cepeda C, Levine MS, Wassum KM (2017) Basolateral amygdala to orbitofrontal cortex projections enable cue-triggered reward expectations. J Neurosci $37: 8374-8384$

Lilja J, Ivaska J (2018) Integrin activity in neuronal connectivity. J Cell Sci 131:jcs212803.

Lim TV, Cardinal RN, Savulich G, Jones PS, Moustafa AA, Robbins TW, Ersche KD (2019) Impairments in reinforcement learning do not explain enhanced habit formation in cocaine use disorder. Psychopharmacology (Berl) 236:2359-2371.

Lo Iacono M, Valzania A, Visco-Comandini F, Aricò E, Viscomi MT, Castiello L, Oddi D, D'Amato FR, Bisicchia E, Ermakova O, PuglisiAllegra S, Carola V (2017) Social threat exposure in juvenile mice promotes cocaine-seeking by altering blood clotting and brain vasculature. Addict Biol 22:911-922.

Lucantonio F, Stalnaker TA, Shaham Y, Niv Y, Schoenbaum G (2012) The impact of orbitofrontal dysfunction on cocaine addiction. Nat Neurosci 15:358-366.

Maekawa M, Ishizaki T, Boku S, Watanabe N, Fujita A, Iwamatsu A, Obinata T, Ohashi K, Mizuno K, Narumiya S (1999) Signaling from Rho to the actin cytoskeleton through protein kinases ROCK and LIM-kinase. Science 285:895-898.

Mackey S, Paulus M (2013) Are there volumetric brain differences associated with the use of cocaine and amphetamine-type stimulants? Neurosci Biobehav Rev 37:300-316.

Malvaez M, Shieh C, Murphy MD, Greenfield VY, Wassum KM (2019) Distinct cortico-amygdala projections drive reward value encoding and retrieval. Nat Neurosci 22:762-769.

Manns JR, Bass DI (2016) The amygdala and prioritization of declarative memories. Curr Dir Psychol Sci 25:261-265.

Mash DC, ffrench-Mullen J, Adi N, Qin Y, Buck A, Pablo J (2007) Gene expression in human hippocampus from cocaine abusers identifies genes which regulate extracellular matrix remodeling. PLoS One 2:e1187.

Menegon A, Burgaya F, Baudot P, Dunlap DD, Girault JA, Valtorta F (1999) $\mathrm{FAK}^{+}$and PYK2/CAK $\beta$, two related tyrosine kinases highly expressed in the central nervous system: similarities and differences in the expression pattern. Eur J Neurosci 11:3777-3788.

Morisot N, Phamluong K, Ehinger Y, Berger AL, Moffat JJ, Ron D (2019) mTORC1 in the orbitofrontal cortex promotes habitual alcohol seeking. Elife 8:e51333

Morini R, Becchetti A (2010) Integrin receptors and ligand-gated channels: integrins and ion channels. In: Advances in experimental medicine and biology (Becchett A, Arcangeli A, eds), p 674. New York NY:Springer-Verlag.

Morsink MC, Steenbergen PJ, Vos JB, Karst H, Joels M, De Kloet ER, Datson NA (2006) Acute activation of hippocampal glucocorticoid receptors results in different waves of gene expression throughout time. J Neuroendocrinol 18:239-252.

Mortillo S, Elste A, Ge Y, Patil SB, Hsiao K, Huntley GW, Davis RL, Benson DL (2012) Compensatory redistribution of neuroligins and N-cadherin following deletion of synaptic $\beta 1$-integrin. J Comp Neurol 520:20412052.

Murakoshi H, Wang H, Yasuda R (2011) Local, persistent activation of Rho GTPases during plasticity of single dendritic spines. Nature 472:100-104.
Murphy MJ, Deutch AY (2018) Organization of afferents to the orbitofrontal cortex in the rat. J Comp Neurol 526:1498-1526.

Newell-Litwa KA, Badoual M, Asmussen H, Patel H, Whitmore L, Horwitz AR (2015) ROCK1 and 2 differentially regulate actomyosin organization to drive cell and synaptic polarity. J Cell Biol 210:225-242.

Niv Y (2019) Learning task-state representations. Nat Neurosci 22:15441553.

Ota KT, Monsey MS, Wu MS, Schafe GE (2010) Synaptic plasticity and NOcGMP-PKG signaling regulate pre- and postsynaptic alterations at rat lateral amygdala synapses following fear conditioning. PLoS One 5:e11236.

Park YK, Goda Y (2016) Integrins in synapse regulation. Nat Rev Neurosci 17:745-756

Parkes SL, Ravassard PM, Cerpa JC, Wolff M, Ferreira G, Coutureau E (2018) Insular and ventrolateral orbitofrontal cortices differentially contribute to goal-directed behavior in rodents. Cereb Cortex 28:2313-2325.

Pitts EG, Li DC, Gourley SL (2018) Bidirectional coordination of actions and habits by TrkB in mice. Sci Rep 8:4495.

Pitts EG, Barfield ET, Woon EP, Gourley SL (2020) Action-outcome expectancies require orbitofrontal neurotrophin systems in naïve and cocaineexposed mice. Neurotherapeutics 17:165-177.

Radley JJ, Anderson RM, Cosme CV, Glanz RM, Miller MC, Romig-Martin SA, LaLumiere RT (2015) The contingency of cocaine administration accounts for structural and functional medial prefrontal deficits and increased adrenocortical activation. J Neurosci 35:11897-11910.

Raghavan S, Bauer C, Mundschau G, Li Q, Fuchs E (2000) Conditional ablation of betal integrin in skin: severe defects in epidermal proliferation, basement membrane formation, and hair follicle invagination. J Cell Biol 150:1149-1160.

Reiner DJ, Lofaro OM, Applebey SV, Korah H, Venniro M, Cifani C, Bossert JM, Shaham Y (2020) Role of projections between piriform cortex and orbitofrontal cortex in relapse to fentanyl seeking after palatable choiceinduced voluntary abstinence. J Neurosci 40:2485-2497.

Rosen GD, Williams AG, Capra JA, Connolly MT, Cruz B, Lu L, Airey DC, Kulkarni K, Williams RW (2000) The mouse brain library. International Mouse Genome Conference, Vol 14, p 166. Available at http://www.mbl. org.

Schilman EA, Uylings HB, Galis-de Graaf Y, Joel D, Groenewegen HJ (2008) The orbital cortex in rats topographically projects to central parts of the caudate-putamen complex. Neurosci Lett 432:40-45.

Schoenbaum G, Setlow B, Saddoris MP, Gallagher M (2003) Encoding predicted outcome and acquired value in orbitofrontal cortex during cue sampling depends upon input from basolateral amygdala. Neuron 39:855-867.

Schubert V, Da Silva JS, Dotti CG (2006) Localized recruitment and activation of RhoA underlies dendritic spine morphology in a glutamate receptor-dependent manner. J Cell Biol 172:453-467.

Schuster T, Krug M, Stalder M, Hackel N, Gerardy-Schahn R, Schachner M (2001) Immunoelectron microscopic localization of the neural recognition molecules L1, NCAM, and its isoform NCAM180, the NCAM-associated polysialic acid, betal integrin and the extracellular matrix molecule tenascin- $\mathrm{R}$ in synapses of the adult rat hippocampus. J Neurobiol 49:142-158

Shapiro LP, Parsons RG, Koleske AJ, Gourley SL (2017a) Differential expression of cytoskeletal regulatory factors in the adolescent prefrontal cortex: implications for cortical development. J Neurosci Res 95:1123-1143.

Shapiro LP, Omar MH, Koleske AJ, Gourley SL (2017b) Corticosteroidinduced dendrite loss and behavioral deficiencies can be blocked by activation of Abl2/Arg kinase. Mol Cell Neurosci 85:226-234.

Shapiro LP, Kietzman HW, Gou J, Rainnie DG, Gourley SL (2019) Rho-kinase inhibition has antidepressant-like efficacy and expedites dendritic spine pruning in adolescent mice. Neurobiol Dis 124:520-530.

Stalnaker TA, Cooch NK, Schoenbaum G (2015) What the orbitofrontal cortex does not do. Nat Neurosci 18:620-627.

Stalnaker TA, Berg B, Aujla N, Schoenbaum G (2016) Cholinergic interneurons use orbitofrotnal input to track beliefs about current state. J Neurosci 36:6242-6257.

Swanson AM, DePoy LM, Gourley SL (2017) Inhibiting Rho kinase promotes goal-directed decision making and blocks habitual responding for cocaine. Nat Commun 8:1861.

Sweis BM, Redish AD, Thomas MJ (2018) Prolonged abstinence from cocaine or morphine disrupts separable valuations during decision conflict. Nat Commun 9:2521. 
Takahashi YK, Stalnaker TA, Marrero-Garcia Y, Rada RM, Schoenbaum G (2019) Expectancy-related changes in dopaminergic error signals are impaired by cocaine self-administration. Neuron 101:294-306.

Thomsen M, Caine SB (2005) Chronic intravenous drug self-administration in rats and mice. Curr Prot Neurosci 9:9.20.

Toda S, Shen HW, Peters J, Cagle S, Kalivas PW (2006) Cocaine increases actin cycling: effects in the reinstatement model of drug seeking. J Neurosci 26:1579-1587.

Urban DJ, Roth BL (2015) DREADDs (designer receptors exclusively activated by designer drugs): chemogenetic tools with therapeutic utility. Annu Rev Pharmacol Toxicol 55:399-417.

Wang W, Kantorovich S, Babayan AH, Hou B, Gall CM, Lynch G (2016) Estrogen's effects on excitatory synaptic transmission entail integrin and TrkB transactivation and depend upon $\beta 1$ integrin function. Neuropsychopharmacology 41:2723-2732.

Warren MS, Bradley WD, Gourley SL, Lin YC, Simpson MA, Reichardt LF, Greer CA, Taylor JR, Koleske AJ (2012) Integrin $\beta 1$ signals through Arg to regulate postnatal dendritic arborization, synapse density, and behavior. J Neurosci 32:2824-2834.

Wassum KM, Izquierdo A (2015) The basolateral amygdala in reward learning and addiction. Neurosci Biobehav Rev 57:271-283.

Whyte AK, Kietzman HW, Swanson AM, Butkovich LM, Barbee BR, Bassell GJ, Gross C, Gourley SL (2019) Reward-related expectations trigger dendritic spine plasticity in the mouse ventrolateral orbitofrontal cortex. J Neurosci 39:4595-4605.
Wiggins AT, Pacchioni AM, Kalivas PW (2009) Integrin expression is altered after acute and chronic cocaine. Neurosci Lett 450:321-323.

Wiggins A, Smith RJ, Shen HW, Kalivas PW (2011) Integrins modulate relapse to cocaine-seeking. J Neurosci 31:16177-16184.

Wilson RC, Takahashi YK, Schoenbaum G, Niv Y (2014) Orbitofrontal cortex as a cognitive map of task space. Neuron 81:267-279.

Yin HH, Ostlund SB, Knowlton BJ, Balleine BW (2005) The role of the dorsomedial striatum in instrumental conditioning. Eur J Neurosci 22:513523.

Zhang Y, Chen K, Sloan SA, Bennett ML, Scholze AR, O'Keeffe S, Phatnani HP, Guarnieri P, Caneda C, Ruderisch N, Deng S, Liddelow SA, Zhang C, Daneman R, Maniatis T, Barres BA, Wu JQ (2014) An RNA-sequencing transcriptome and splicing database of glia, neurons, and vascular cells of the cerebral cortex. J Neurosci 34:11929-11947.

Zhou Z, Meng Y, Asrar S, Todorovski Z, Jia Z (2009) A critical role of Rhokinase ROCK2 in the regulation of spine and synaptic function. Neuropharmacology 56:81-89.

Zimmermann KS, Yamin JA, Rainnie DG, Ressler KJ, Gourley SL (2017) Connections of the mouse orbitofrontal cortex and regulation of goaldirected action selection by brain-derived neurotrophic factor. Biol Psychiatry 81:366-377.

Zimmermann KS, Li CC, Rainnie DG, Ressler KJ, Gourley SL (2018) Memory retention involves the ventrolateral orbitofrontal cortex: comparison with the basolateral amygdala. Neuropsychopharmacology 43:373-383 